\title{
Simulated zonal current characteristics in the southeastern tropical Indian Ocean (SETIO)
}

\author{
Nining Sari Ningsih ${ }^{1}$, Sholihati Lathifa Sakina ${ }^{2}$, Raden Dwi Susanto ${ }^{3,2}$, and Farrah Hanifah ${ }^{1}$ \\ ${ }^{1}$ Research Group of Oceanography, Faculty of Earth Sciences and Technology, \\ Bandung Institute of Technology, Bandung, Indonesia \\ ${ }^{2}$ Department of Oceanography, Faculty of Earth Sciences and Technology, \\ Bandung Institute of Technology, Bandung, Indonesia \\ ${ }^{3}$ Department of Atmospheric \& Oceanic Science, University of Maryland, College Park, USA
}

Correspondence: Nining Sari Ningsih (nining@ fitb.itb.ac.id)

Received: 11 September 2020 - Discussion started: 12 October 2020

Revised: 5 May 2021 - Accepted: 2 July 2021 - Published: 23 August 2021

\begin{abstract}
Detailed ocean currents in the southeastern tropical Indian Ocean adjacent to southern Sumatran and Javan coasts have not been fully explained because of limited observations. In this study, zonal current characteristics in the region have been studied using simulation results of a $1 / 8^{\circ}$ global hybrid coordinate ocean model from 1950 to 2013. The simulated zonal currents across three meridional sections were then investigated using an empirical orthogonal function (EOF), where the first three modes account for $75 \%-98 \%$ of the total variance. The first temporal mode of EOF is then investigated using ensemble empirical mode decomposition (EEMD) to distinguish the signals.

This study has revealed distinctive features of currents in the South Java Current (SJC) region, the Indonesian Throughflow (ITF)-South Equatorial Current (SEC) region, and the transition zone between these regions. The vertical structures of zonal currents in southern Java and offshore Sumatra are characterized by a one-layer flow. Conversely, a two-layer flow is observed in the nearshore and transition regions of Sumatra. Current variation in the SJC region has peak energies that are sequentially dominated by semiannual, intraseasonal, and annual timescales. Meanwhile, the transition zone is characterized by semiannual and intraseasonal periods with pronounced interannual variations. In contrast, interannual variability associated with El Niño-Southern Oscillation (ENSO) and the Indian Ocean Dipole (IOD) modulates the prominent intraseasonal variability of current in the ITF-SEC region. ENSO has the strongest influence at the outflow ITF, while the IOD's strongest influence is in south-
\end{abstract}

western Sumatra, with the ENSO (IOD) leading the current by 4 months ( 1 month). Moreover, the contributions (largest to smallest) of each EEMD mode at the nearshore of Java and offshore Sumatra are intraseasonal, semiannual, annual, interannual, and long-term fluctuations. The contribution of long-term variation $(19.2 \%)$ in the far offshore eastern Indian Ocean is larger than the interannual $(16.3 \%)$ and annual $(14.7 \%)$ variations. Future studies should be conducted to investigate this long-term variation.

\section{Introduction}

The southeastern tropical Indian Ocean (SETIO) plays an important role in ocean and atmosphere dynamics of Indian Ocean. Several features make the SETIO region unique. This is partly due to the presence of the Indonesian Throughflow (ITF) (Gordon, 1986; Wyrtki, 1987; Murray and Arief 1988; and publications made thereafter), which transfers warm and fresh Pacific waters to the Indian Ocean and contributes to variability of sea surface temperature (SST) in the SETIO, particularly in the area off Java and Sumatra, which in turn affects the climate system both at regional and global scales (Clark et al., 2003; Saji and Yamagata, 2003). In the SETIO, the complex dynamical circulations exist due to the coexistence of the South Java Current (SJC), South Java Undercurrent (SJUC), South Equatorial Current (SEC), and the ITF, which originates from the outflow passages (e.g., Sunda, Lombok, and Ombai straits and the Timor Passage) and their 
mutual interactions. It has been recognized that the SJC and SJUC play an important role in distributing warm and fresh water into and out of the southeastern Indian Ocean and in turn influence the global climate system (e.g., Fieux et al., 1994, 1996; Sprintall et al., 1999, 2010; Wijffels et al., 2002; Wijffels and Meyers, 2004).

Previous studies have suggested that the current dynamics in the SETIO, as well as ocean circulations in the inner Indonesian seas, are strongly linked to the regional IndoPacific and global climates from intraseasonal, seasonal, interannual, and even longer timescales (e.g., Sprintall et al., 1999; Song et al., 2004; Iskandar et al., 2006; Yuan et al., 2008; Syamsudin and Kaneko, 2013; Sprintall and Révelard, 2014; Krishnamurthy and Krishnamurthy, 2016; Susanto et al., 2016). On an intraseasonal timescale, Iskandar et al. (2006) have confirmed the existence of intraseasonal variations of SJC and its deeper undercurrent (SJUC) along the southern Sumatran and Javan coasts using simulations from an ocean general circulation model (OGCM) for 13 years (1990-2003). They found that the intraseasonal SJC is dominated by the $90 \mathrm{~d}$ variations associated with propagation of the first baroclinic Kelvin waves, which are driven by strong $90 \mathrm{~d}$ winds over the central equatorial Indian Ocean. Meanwhile, $60 \mathrm{~d}$ variations are the dominant feature in the SJUC, which are forced by intraseasonal atmospheric variability associated with the eastward movement of the Madden-Julian Oscillation (MJO) over the eastern equatorial Indian Ocean.

On a seasonal timescale, variabilities of SJC and SJUC that exist along the coasts of western Sumatra and southern Java have been investigated based on observation data (e.g., Sprintall et al., 1999, 2010; Qu and Meyers, 2005). In general, their studies have revealed that the SJC is eastward during the northwest (NW) monsoon (December to February; DJF) and that the eastward-flowing SJC is enhanced in the presence of semiannual coastal Kelvin waves originating in the equatorial Indian Ocean during the first (March to May; MAM) and second (September to November; SON) transitional monsoons. During the southeast (SE) monsoon (July to August; JJA), the SJC flows mostly westward. In addition, Sprintall et al. (2010) have confirmed the extension of SJC and SJUC into the Ombai Strait through the Sawu Sea based on 3-year velocity measurements (2004-2006).

Moreover, like SJC, ITF also has seasonal variability. Sprintall et al. (2009) have examined the ITF transport in three exit passages, namely the Lombok and Ombai straits and Timor Passage, using INSTANT (International Nusantara STratification ANd Transport) data from January 2003 through December 2006. Their results show that seasonal variations of the ITF are influenced by the monsoon climate, with maximum ITF occurring during the SE monsoon. Under the El Niño-Southern Oscillation (ENSO) cycle, interannual variability of ENSO also affects the ITF transport, in which ENSO-related wind forcing is found to modulate the variability of ITF transport, which strengthened (weakened) during La Niña (El Niño) (Susanto et al., 2012; Susanto and
Song, 2015; Feng et al., 2018). In addition to ENSO, Pujiana et al. (2019) have revealed that Indian Ocean Dipole (IOD) was also responsible for the anomalous ITF. They found a reduction in the ITF transport in 2016 due to an unprecedented negative IOD event. Feng et al. (2018) also reported the presence of decadal and interdecadal variations of the ITF transport, mostly due to the ITF responses to atmospheric forcing (trade winds) and oceanic adjustment in the Pacific (Meng et al., 2004; Feng et al., 2018). In addition to the wind forcing mechanism, fluctuations in rainfall over the Indonesian seas that modulate salinity also influence the ITF transport on interannual (Hu and Sprintall, 2016) and decadal (Hu and Sprintall, 2017; Jyoti et al., 2019) timescales. They found that the salinity effect mechanism is an important component of ITF dynamics and that it is different from the wind forcing mechanism. Moreover, it has been revealed that the salinity effect contributes $36 \%$ of the total interannual variability of the ITF transport (Hu and Sprintall, 2016) and dominated an increasing trend of the ITF transport during the past decade (Hu and Sprintall, 2017).

In the offshore area of the SETIO, it has been reported that the SEC in the southern waters of Java has an intraseasonal variation on a $60 \mathrm{~d}$ timescale (e.g., Quadfasel and Cresswell, 1992; Semtner and Chervin, 1992; Bray et al., 1997). Further research carried out by Feng and Wijffels (2002) showed that baroclinic instability seems to be the main cause of intraseasonal variability in the SEC. Moreover, it is known that the SEC in the southern Indian Ocean bifurcates at the eastern coast of Madagascar into the Northeast Madagascar Current (NEMC) and Southeast Madagascar Current (SEMC). Yamagami and Tozuka (2015) have investigated interannual variability of the SEC bifurcation along the Madagascar coast. Their results indicate that interannual variation of SEC bifurcation latitude and the NEMC and SEMC transports are correlated with Niño 3.4 index, with a lag of about 5-15 months. However, the seasonal and interannual variations of SEC in the SETIO are still unclear.

Regarding dynamics and characteristics of the SETIO, especially adjacent to the western coast of Sumatra and the southern coast of Java, previous studies are either based on a numerical model, remote sensed data, or velocity or mooring observations within the Indonesian seas or at the exit passages of Indonesian seas (Sunda, Lombok, Ombai, and Timor passages), which lead into the SETIO. There is almost no ocean current or velocity measurement within the SETIO. The observational velocity data are available only at limited points in space and time. The first velocity measurement in the SETIO region was reported by Sprintall et al. (1999). The mooring was deployed in $200 \mathrm{~m}$ water depth off the southern coast of Java at $8.19^{\circ} \mathrm{S}, 109.53^{\circ} \mathrm{E}$ from March 1997 to March 1998 at depths of 55,115, and $175 \mathrm{~m}$, but only the current meters at 115 and $175 \mathrm{~m}$ were fully working properly (Sprintall et al., 1999). It should be underlined that the period of velocity measurement was conducted during strong El Niño and positive IOD episodes. Hence, not only might 
the observed currents not characterize the neutral years, but its characteristics might also not be fully resolved due to this limited vertical resolution. Another velocity measurement at the southern coast of Java with a relatively high vertical resolution is collected by RAMA (Research Moored Array for African-Asian-Australian Monsoon Analysis and Prediction). The RAMA mooring was installed at $8.5^{\circ} \mathrm{S}, 106.75^{\circ} \mathrm{E}$ (indicated by point $\mathrm{R}_{2}$ in Fig. 1), and it provides current data for a period of 17 months (December 2008 to May 2010) from the near surface down to a depth of $136 \mathrm{~m}$ with a vertical resolution of $8 \mathrm{~m}$. Due to this limited duration of observed currents, it might hard to resolve variations on timescales greater than the semiannual cycle. Recently, there are some moorings to measure velocity and stratification deployed in the SETIO region. However, they have not been fully recovered or published. Therefore, due to the limited duration of in situ velocity measurements and the limited number of observation points in the SETIO, the detailed dynamics and characteristics of ocean currents in the region are not fully understood yet. It is important to obtain a better understanding of current characteristics, as well as their spatial and temporal variations in the SETIO adjacent to the southern coasts of Sumatra and Java, both for scientific and practical reasons, such as fisheries, climate, and navigation. These are the main motivations of the present study.

In addition, many studies of the current dynamic in the SETIO adjacent to the southern coasts of Sumatra and Java, which were carried out by the previous investigators mentioned above (i.e., Sprintall et al., 1999, 2010; Qu and Meyers, 2005; Iskandar et al., 2006), focused on intraseasonal and seasonal variations based on relatively limited observation periods and measured data points. To the best of our knowledge, research concerning features of zonal currents in the SETIO, especially in regions of SJC, ITF and SEC, and the transition zone between these regions, as well as their interannual and long-term variations, has so far not been extensively performed in these regions, either based on observations or numerical models. It is necessary to acquire better and comprehensive insights into both spatial and temporal characteristics of the current circulation in the region. Hence, the aims of this paper are (1) to further investigate basic features and mode structures of the current vertical profile time series and their temporal variability in the SETIO adjacent to the Sumatran and Javan southern coasts based on relatively long-term data (64 years) derived from simulated results of a $1 / 8^{\circ}$ global version of the HYbrid Coordinate Ocean Model (HYCOM); (2) to better understand variability of the zonal current in the area of study, especially on intraseasonal, seasonal, and interannual timescales, by using a combination of empirical orthogonal function (EOF) analysis and the ensemble empirical mode decomposition (EEMD) method (i.e., Huang et al., 1998; Wu and Huang, 2009; Shen et al., 2017, and publications made thereafter); and (3) to comprehensively discuss the ocean current characteristics in the SETIO and subsequently elaborate their genesis.

\section{Data and methods}

The HYCOM has been successfully used by previous investigators to simulate current circulation within the Indonesian waters (e.g., Gordon et al., 2008; Metzger et al., 2010; Shinoda et al., 2012). In this study, we analyzed the monthly mean HYCOM simulated currents with $1 / 8^{\circ}$ horizontal resolution for the period of 64 years (1950-2013). Simulation results of the HYCOM version used in this study have been verified against several data, and the verifications have been documented in our earlier publications (Hanifah and Ningsih, 2016). In addition to the aforementioned comparisons, in this paper we have performed comparisons between the moored RAMA provided by National Oceanic and Atmospheric Administration (NOAA) and the HYCOM currents at two points (marked by points $\mathrm{R}_{1}$ and $\mathrm{R}_{2}$ ) and also comparisons between OSCAR (Ocean Surface Current Analysis Real-time) and the HYCOM currents at three points (marked by points $\mathrm{O}_{1}$, $\mathrm{O}_{2}$, and $\mathrm{O}_{3}$ ), as shown in Fig. 1. The RAMA and OSCAR datasets have been provided by NOAA (https://www.pmel. noaa.gov/tao/data_deliv/deliv-nojava-rama.html, last access: 19 April 2020) and the Physical Oceanography Distributed Active Archive Center (PODAAC) (https://podaac. jpl.nasa.gov/dataset/OSCAR_L4_OC_third-deg, last access: 29 April 2020), respectively. The general agreement between the HYCOM currents and those of the moored RAMA is reasonably encouraging, with the correlation coefficient $(r)$ ranging from 0.40 to 0.57 at point $\mathrm{R}_{1}$ (Fig. $1 \mathrm{e}-\mathrm{h}$ ) and 0.49 to 0.55 at point $\mathrm{R}_{2}$ (Fig. $1 \mathrm{i}-\mathrm{k}$ ), with the $95 \%$ significance level at both points approximately \pm 0.04 and \pm 0.09 , respectively. In addition, the root-mean-square errors (RMSEs) between them range from 0.10 to $0.28 \mathrm{~m} \mathrm{~s}^{-1}$ at point $\mathrm{R}_{1}$ and 0.17 to $0.29 \mathrm{~m} \mathrm{~s}^{-1}$ at point $\mathrm{R}_{2}$. Meanwhile, the comparisons between the HYCOM currents and the OSCAR data also show general agreement at points $\mathrm{O}_{1}\left(r=0.65 ; \mathrm{RMSE}=0.17 \mathrm{~m} \mathrm{~s}^{-1}\right)$, $\mathrm{O}_{2} \quad\left(r=0.59 ; \quad \mathrm{RMSE}=0.19 \mathrm{~m} \mathrm{~s}^{-1}\right), \quad$ and $\mathrm{O}_{3} \quad(r=0.60$; RMSE $\left.=0.21 \mathrm{~m} \mathrm{~s}^{-1}\right)$, with the $95 \%$ significance level at the three points being \pm 0.13 (Fig. 1b-d). Further details of the numerical model description of this applied HYCOM version can be found in Hanifah and Ningsih (2016). In addition to the HYCOM-simulated currents, to support analysis in this research, the Oceanic Niño and Dipole Mode Indices (ONI and DMI, respectively) were used to identify climate conditions and influences of interannual forcing associated with ENSO and IOD on interannual variability of the zonal currents in the study region. The ONI and DMI were obtained from NOAA website (http://www.cpc. ncep.noaa.gov/data/indices/, last access: 21 February 2021) and the Japan Agency for Marine Earth Science and Technology (JAMSTEC) website (http://www.jamstec.go.jp/ frcgc/research/d1/iod/iod/dipole_mode_index.html, last access: 21 February 2021), respectively. In addition, the wind fields derived from NOAA (https://www.esrl.noaa.gov/psd/ data/gridded/data.ncep.reanalysis.derived.surface.html, last 
(a)

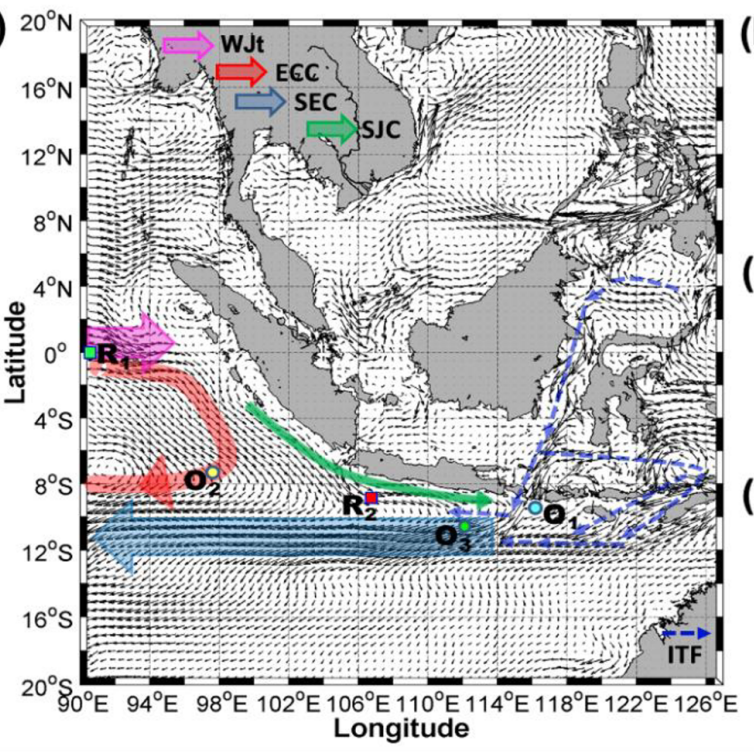

RMSE $=0.28 \mathrm{~m} \mathrm{~s}^{-1}$

(e)

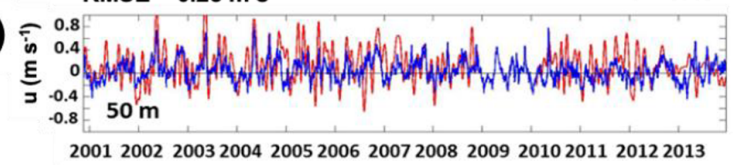

(f)

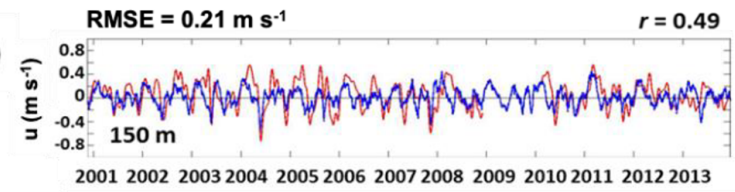

(g)

RMSE $=0.11 \mathrm{~m} \mathrm{~s}^{-1} \quad r=0.57$

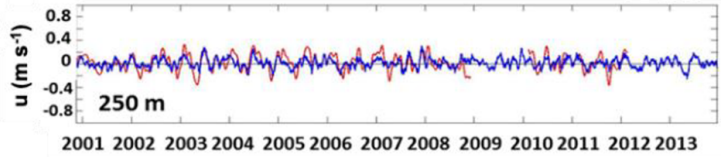

(h)

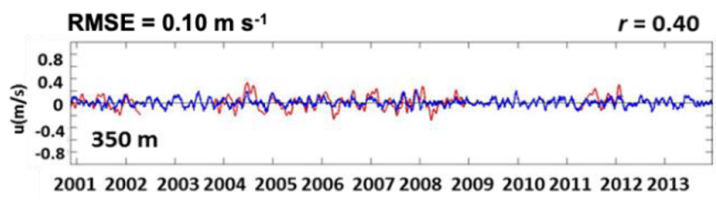

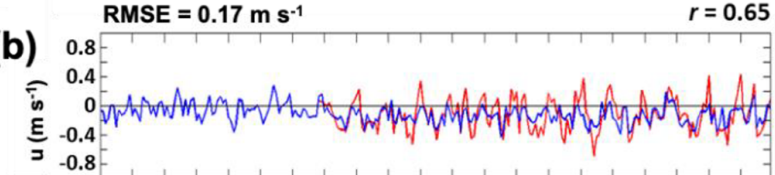

$\begin{array}{llllllll}1993 & 1995 & 1997 & 1999 & 2001 & 2003 & 2005 & 2007 \\ 2009 & 2011 & 2013\end{array}$

(C)

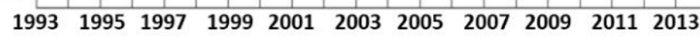

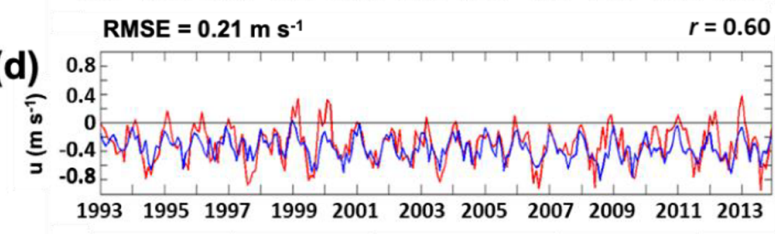

OSCAR — HYCOM

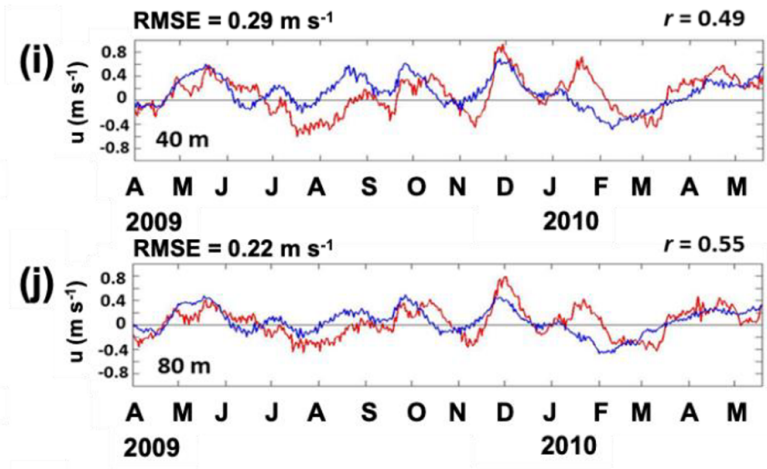

RMSE $=0.17 \mathrm{~m} \mathrm{~s}^{-1} \quad r=0.52$

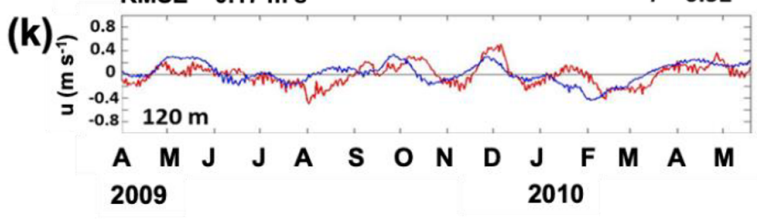

RAMA

Figure 1. Validation of HYCOM zonal currents with OSCAR and RAMA datasets. (a) Locations of validation points are as follows: points $\mathrm{O}_{1}\left(8^{\circ} \mathrm{S}, 116^{\circ} \mathrm{E}\right), \mathrm{O}_{2}\left(7^{\circ} \mathrm{S}, 98^{\circ} \mathrm{E}\right)$, and $\mathrm{O}_{3}\left(11.5^{\circ} \mathrm{S}, 113^{\circ} \mathrm{E}\right)$ show the OSCAR data, while $\mathrm{R}_{1}\left(0^{\circ} \mathrm{S}, 90^{\circ} \mathrm{E}\right)$ and $\mathrm{R}_{2}\left(8.5^{\circ} \mathrm{S}, 106.75^{\circ} \mathrm{E}\right)$ show the RAMA data. (b-d) Time series of the zonal currents observed by the HYCOM (blue lines) and the OSCAR (red lines) at a depth of $0.5 \mathrm{~m}$ at points $\mathrm{O}_{1}, \mathrm{O}_{2}$, and $\mathrm{O}_{3}$, respectively. Meanwhile (e)-(h) are the time series of zonal currents observed by the $\mathrm{HYCOM}$ (blue lines) and the moored RAMA (red lines) at point $\mathrm{R}_{1}$ sequentially at depths of 50, 150, 250, and $350 \mathrm{~m}$. Meanwhile, (i)-(k) are the same as (e)-(h), except for being for point $\mathrm{R}_{2}$ at depths of 40,80 , and $120 \mathrm{~m}$,. In (e)-(h) (point $\mathrm{R}_{1}$ ), a monthly low-pass filter has been applied before plotting. RMSE stands for root-mean-square error, $r$ shows the correlation coefficients.

access: 17 May 2020) are also used to investigate the effects of local and remote winds on zonal current variations.

The EOF method (i.e., Kantha and Clayson, 2000; Hannachi, 2004) was then used to investigate the mode structure of the zonal current vertical profile and its temporal variabil- ity, particularly at points $\mathrm{A}_{\mathrm{SM}}, \mathrm{A}_{\mathrm{WJ}}$, and $\mathrm{A}_{\mathrm{EJ}}$ (Transect $\mathrm{A}$ ); points $\mathrm{B}_{\mathrm{SM}}, \mathrm{B}_{\mathrm{WJ}}$, and $\mathrm{B}_{\mathrm{EJ}}$ (Transect $\mathrm{B}$ ); and points $\mathrm{C}_{\mathrm{SM}}$, $\mathrm{C}_{\mathrm{WJ}}$, and $\mathrm{C}_{\mathrm{EJ}}$ (Transect $\mathrm{C}$ ), as shown in Fig. 2. Moreover, temporal variability of the first EOF mode of zonal current was analyzed by applying the EEMD method for decompos- 


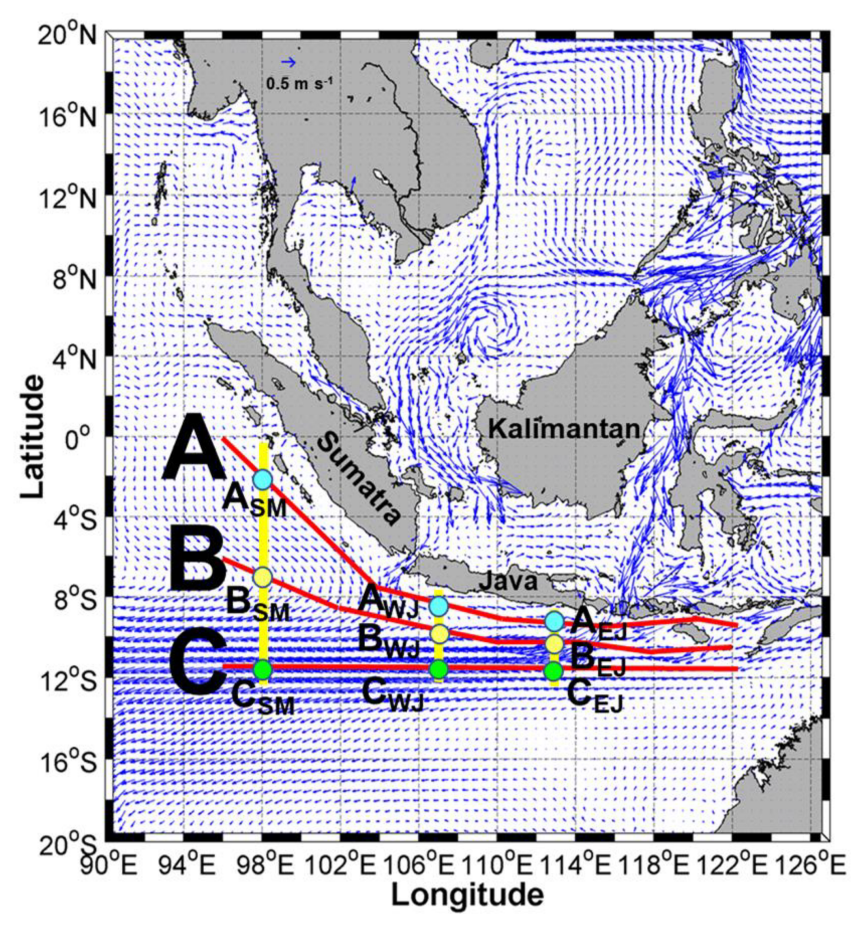

Figure 2. The area of study interest in the SETIO region adjacent to the Sumatran and Javan southern coasts. The blue arrows show climatological (yearly mean) surface $(1 \mathrm{~m})$ current field over 64 years from 1950 to 2013. Yellow lines are the meridional sections along the three longitudes $\left(98,107\right.$, and $\left.113^{\circ} \mathrm{E}\right)$, while red lines are the three selected transects: A, B, and C. Green, yellow, and cyan circles are the locations in which the zonal currents are analyzed, namely points $\mathrm{A}_{\mathrm{SM}}, \mathrm{A}_{\mathrm{WJ}}, \mathrm{A}_{\mathrm{EJ}}$ (on Transect $\mathrm{A}$ ); points $\mathrm{B}_{\mathrm{SM}}, \mathrm{B}_{\mathrm{WJ}}$, and $\mathrm{B}_{\mathrm{EJ}}$ (on Transect $\mathrm{B}$ ); and points $\mathrm{C}_{\mathrm{SM}}, \mathrm{C}_{\mathrm{WJ}}$, and $\mathrm{C}_{\mathrm{EJ}}$ (on Transect $\mathrm{C}$ ). The subscripts SM, WJ, and EJ denote regions which are close to Sumatra, West Java, and East Java, respectively.

ing a signal into a series of intrinsic mode functions and investigating the zonal current variability in the SETIO region adjacent to the southern coasts of Sumatra and Java. Furthermore, a power spectral analysis (Emery and Thomson, 2001) was applied to the EEMD results to identify dominant periods of the zonal current variability in the study area. The power spectral analysis is computed from a measured time series by cutting the time series into several segments and applying Fourier analysis to these segments. The contribution from individual Fourier harmonics was subsequently summed to derive total energy of time series. In addition, $95 \%$ confidence red noise level in the power spectrum, specified to acquire accurate confidence thresholds for true periodic signatures, was calculated based on number of degrees of freedom in each frequency band (Mann and Lees, 1996).

\section{Results}

\subsection{Distinctive features of zonal currents in the study area}

As we are interested in investigating characteristics of the main ocean currents that exist in the SETIO adjacent to the Sumatran and Javan southern coasts, such as the SJC, ITF, and SEC, in this study we only considered major components of those currents, namely the zonal current component, which was analyzed from the surface to $800 \mathrm{~m}$ depth. The maximum depth of $800 \mathrm{~m}$ was chosen to capture the presence of prevailing ocean currents in the area of study and the surrounding regions, such as cores of the SJUC. For example, these cores in the Ombai Strait exist at about 400-800 m depth (Sprintall et al., 2010). Furthermore, based on monthly averaged surface currents over a 64-year period (1950-2013), we analyzed the zonal currents at three transects, namely Transects A, B, and C, which represent the coastal region, the transition zone between coastal and offshore regions, and the offshore region, respectively (Fig. 2). Transects $\mathrm{A}$ and $\mathrm{C}$ were selected with respect to the prevalence of ocean currents in the area of interest, representing nearshore (SJC) and offshore (ITF-SEC) areas, respectively (Qu and Meyers, 2005; Fang et al., 2009; Ding et al., 2013). In the present study, we have performed additional analyses of current characteristics of Transect B as the transition zone between the SJC region (Transect A) and ITF-SEC region (Transect $\mathrm{C}$ ) due to the existence of typical features of zonal currents along the three transects $(\mathrm{A}, \mathrm{B}$, and $\mathrm{C})$, as shown in Fig. 2.

To support our reasons for assigning the three transects, we have provided Fig. 3 (as an example), which clearly shows the particular features of near-surface zonal currents along the three transects. Dynamics of zonal surface currents on Transect A (Fig. 3c), especially along the southern coasts of Sumatra and Java $\left(98-114^{\circ}\right.$ E), show a complex interplay between remote wind forcings from both the equatorial Indian and Pacific Oceans and local wind. In general, there are enhanced eastward-flowing currents during MAM and SON, which are probably attributed to Kelvin wave passage. Seasonal characteristics of zonal currents associated with local wind, which is eastward (westward) during DJF (JJA), especially along the southern coast of Java, can be clearly seen after 6-12 months of band-pass filtering (figure not shown). In contrast, westward currents are dominant along Transect C (Fig. 3e). Meanwhile, although westward currents are quite dominant along Transect $\mathrm{B}$, eastward currents are also present, especially at longitudes $95-107^{\circ} \mathrm{E}$ (Fig. 3d). Here, longitude-depth plots of mean zonal currents along sections $\mathrm{A}, \mathrm{B}$, and $\mathrm{C}$ are also presented in Fig. 4, which clearly shows the different zonal current system along the transects. Mean zonal currents along Transect A (Fig. 4a) show two distinguishing features: (1) the mean currents dominantly flow eastward from the sea surface to $100 \mathrm{~m}$ depth 
$\left(95-114^{\circ} \mathrm{E}\right)$, and (2) they are predominantly westward from $115^{\circ} \mathrm{E}$ to $122^{\circ} \mathrm{E}$. The $115^{\circ} \mathrm{E}$ longitude line is a region that is close to the Lombok Strait (LS; one of the ITF exit passages). In addition, the mean eastward current at $\mathrm{A}_{\mathrm{EJ}}$ also exists at depths beneath $100 \mathrm{~m}$ and reaches about $0.03 \mathrm{~m} \mathrm{~s}^{-1}$ at $\sim 400 \mathrm{~m}$. Meanwhile, the average current on Transect B (the transitional zone) is westward, especially at longitudes 101 to $107^{\circ} \mathrm{E}$ (Fig. 4b). In the offshore region (Transect C), the mean zonal current flows westward throughout the region (Fig. 4c).

Moreover, we also presented meridional sections of zonal current along the three longitudes (yellow lines in Fig. 2) to justify the selection of the locations for analyzing zonal current characteristics, namely sections Sumatra $\left(\mathrm{SM} ; 98^{\circ} \mathrm{E}\right)$, West Java (WJ; $\left.107^{\circ} \mathrm{E}\right)$, and East Java $\left(\mathrm{EJ} ; 113^{\circ} \mathrm{E}\right)$, as shown in Fig. 5 (as an example). Figure 5 clearly shows the typical features of near-surface zonal currents along the three meridional sections, namely the coastal (SJC) area $\left(0-\sim 2.5^{\circ} \mathrm{S}\right.$ at $\mathrm{SM} ; \sim 7-8.5^{\circ} \mathrm{S}$ at $\mathrm{WJ}$; and $\sim 8-9.5^{\circ} \mathrm{S}$ at EJ $)$, the transitional zone $\left(\sim 2.5-9^{\circ} \mathrm{S}\right.$ at $\mathrm{SM} ; \sim 8.5-10^{\circ} \mathrm{S}$ at $\mathrm{WJ}$; and $\sim 9.5-$ $10.5^{\circ} \mathrm{S}$ at EJ); and the offshore (ITF-SEC) area $\left(\sim 9-12^{\circ} \mathrm{S}\right.$ at $\mathrm{SM} ; \sim 10-12^{\circ} \mathrm{S}$ at $\mathrm{WJ}$; and $\sim 10.5-12^{\circ} \mathrm{S}$ at $\left.\mathrm{EJ}\right)$.

Furthermore, because we are specifically interested in zonal current characteristics off southern waters of Sumatra and Java, we selected three points on each transect, namely points $A_{S M}, A_{W J}$, and $A_{E J}$ on Transect $A$; points $B_{S M}, B_{W J}$, and $\mathrm{B}_{\mathrm{EJ}}$ on Transect $\mathrm{B}$; and points $\mathrm{C}_{\mathrm{SM}}, \mathrm{C}_{\mathrm{WJ}}$, and $\mathrm{C}_{\mathrm{EJ}}$ on Transect $\mathrm{C}$ with respect to the particular features of zonal currents shown in Figs. 2, 3c-e, and 4-5. Here, the subscripts $\mathrm{SM}, \mathrm{WJ}$, and EJ of the nine selected points represent regions that are close to Sumatra, West Java, and East Java, respectively.

\subsection{Climatological current fields}

Based on the unique features of near-surface zonal currents along the three meridional sections $\left(\mathrm{EJ}\right.$ : $\mathrm{A}_{\mathrm{EJ}}-\mathrm{B}_{\mathrm{EJ}}-\mathrm{C}_{\mathrm{EJ}}$; WJ: $\mathrm{A}_{\mathrm{WJ}}-\mathrm{B}_{\mathrm{WJ}}-\mathrm{C}_{\mathrm{WJ}}$; and $\mathrm{SM}$ : $\mathrm{A}_{\mathrm{SM}}-\mathrm{B}_{\mathrm{SM}}-\mathrm{C}_{\mathrm{SM}}$ in Fig. 2 ) as shown in Fig. 5, we further investigated the vertical structure of zonal current along the sections. Figure 6 shows seasonal mean profiles of zonal current velocity and its average (the climatological current field) over a period of 64 years (19502013). Seasonal variations in the zonal currents were analyzed during DJF, MAM, JJA, and SON at each point (Sections EJ, WJ, and SM), as shown in Fig. 2. It can be clearly seen in Fig. 6 that there are special characteristics of the mean zonal currents on each meridional transect (denoted by black lines in Fig. 6). In the following subsections, we analyze the climatological current fields of each meridional transect.

\subsubsection{Vertical structure of zonal current along the meridional section of East Java $\left(A_{E J}-B_{E J}-C_{E J}\right)$}

A different zonal current system along the meridional transect of East Java $\left(\mathrm{EJ} ; \mathrm{A}_{\mathrm{EJ}}-\mathrm{B}_{\mathrm{EJ}}-\mathrm{C}_{\mathrm{EJ}}\right)$ can clearly be seen in
Fig. 6a-f. On average, for the period 1950 through 2013, zonal climatological current at $\mathrm{A}_{\mathrm{EJ}}$ (nearshore area) generally flows eastward from the sea surface to $100 \mathrm{~m}$ depth (Fig. 6a and d) and reaches a maximum value of about $0.16 \mathrm{~m} \mathrm{~s}^{-1}$. It is suggested that the average zonal current at this point is mainly attributed to SJC, and it shows seasonal variations. During the SE monsoon (JJA), the strength of climatological eastward SJC at this point in upper $10 \mathrm{~m}$ depth reduces (Fig. 6d). Meanwhile, during the NW monsoon (DJF), the current in the upper $10 \mathrm{~m}$ (Fig. 6d) flows more eastward in response to the prevailing northwesterly winds (Fig. 7). In general, the mean eastward current at $A_{E J}$, during DJF was attributed to local winds. Interestingly, during this monsoon period (DJF), the eastward current at $\mathrm{A}_{\mathrm{EJ}}$, particularly that at depths beneath $100 \mathrm{~m}$, strengthens and occurs up to $\sim 800 \mathrm{~m}$. Other physical processes may account for the enhanced eastward current at this point. The SJC and SJUC, which are seasonally varying currents and predominantly eastward, are defined as the surface current in the upper $150 \mathrm{~m}$ and the subsurface current beneath $150 \mathrm{~m}$ down to $1000 \mathrm{~m}$, respectively (Iskandar et al., 2006). The eastwardflowing SJC and SJUC are intensified, coinciding with the arrival of a seasonal downwelling Kelvin wave along the southern coast of Java (e.g., Sprintall et al., 1999, 2000; Iskandar et al., 2006). Downwelling Kelvin waves originating in the equatorial Indian Ocean during the transitional monsoons propagate along the coasts of western Sumatra and southern Java with phase speeds ranging from 1.5 to $2.9 \mathrm{~m} \mathrm{~s}^{-1}$ (e.g., Sprintall et al., 2000; Syamsudin et al., 2004; Iskandar et al., 2005). These phase speeds indicate that the downwelling Kelvin waves will arrive at $A_{E J}$ in $21-41$ d. In this case, downwelling Kelvin waves generated during the monsoon transition period in November may arrive at $\mathrm{A}_{\mathrm{EJ}}$ in December-January. Therefore, in addition to the local eastward winds, the downwelling Kelvin waves may also contribute to strengthen the eastward currents at $\mathrm{A}_{\mathrm{EJ}}$ during the NW monsoon, including those at depths beneath $100 \mathrm{~m}$.

Meanwhile, the average current at $\mathrm{B}_{\mathrm{EJ}}$ (the transitional zone) is westward. It is suggested that the mean westward current at the point $\mathrm{B}_{\mathrm{EJ}}$ is more dominated by the ITF (shown by black lines in Fig. 6b and e). Based on observations of the exit passages (Lombok Strait, Timor Passage, and total ITF along exit passages), ITF in JJA is stronger than that in DJF (e.g., Sprintall et al., 2009). In this study, however, it is found that westward current at the point $\mathrm{B}_{\mathrm{EJ}}$ at $100 \mathrm{~m}$ depth is stronger during DJF than JJA. This phase changing (delay) of the ITF seasonality from JJA to DJF at this point is also found in the Ombai Strait as documented by Sprintall et al. (2009, their Table 3; 2010, their Fig. 3). Moreover, Sprintall et al. (2010) found cores of subsurface maximum ITF during DJF extending from $100-250 \mathrm{~m}(100-800 \mathrm{~m})$ depth at the northern (southern) part of the strait. In the present study, this seasonal feature of the subsurface maximum ITF is also found at $\mathrm{B}_{\mathrm{EJ}}$, in which the corresponding westward current at this point reaches its maximum values at $\sim 100 \mathrm{~m}$ depth and 


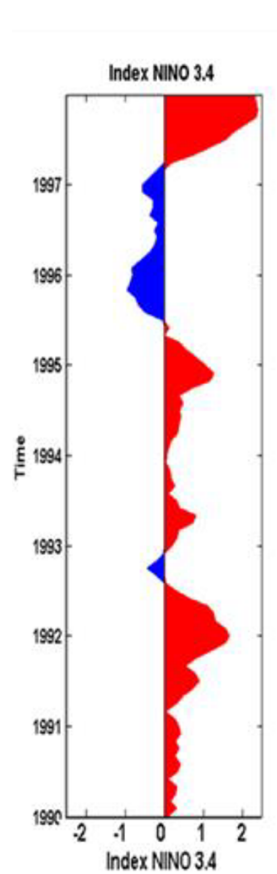

(a)

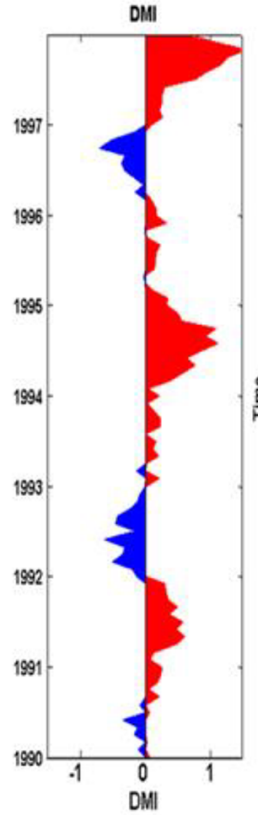

(b)

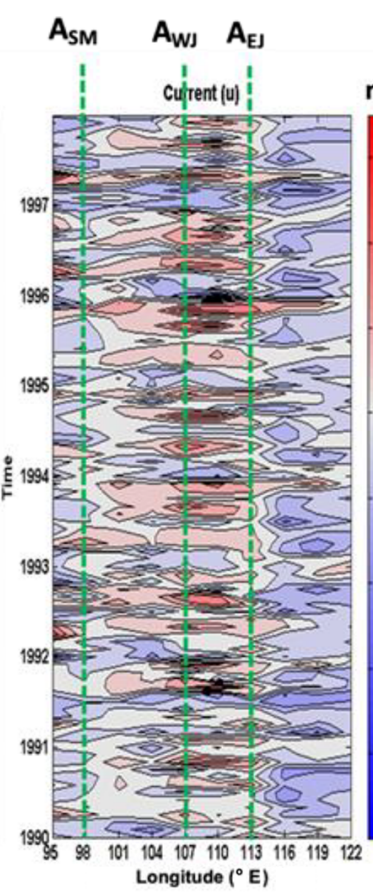

(c)

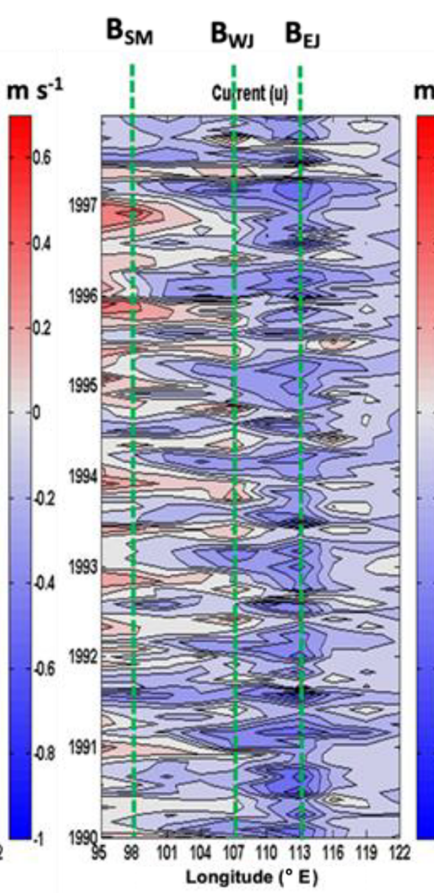

(d)

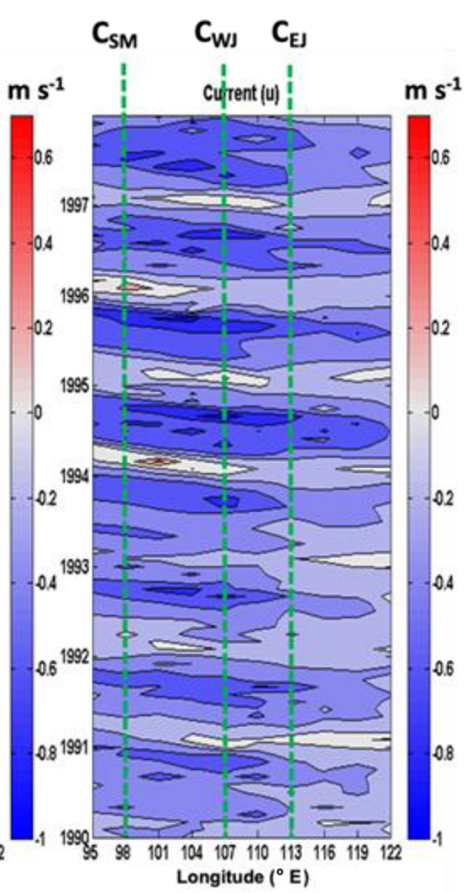

(e)

Figure 3. Time-longitude profiles of (a) ONI and (b) DMI and monthly averages of surface (1 m) zonal currents along (c) Transect A, (d) Transect B, and (e) Transect C. Positive (negative) values of the zonal currents indicate eastward (westward) currents. Meanwhile, dashed green lines denote the longitudes of the nine selected points.

the maximum westward current is stronger during DJF than JJA (Fig. $6 \mathrm{~b}$ and e). Hence, we suggest that the primary driver for zonal westward current at $\mathrm{B}_{\mathrm{EJ}}$ is the ITF coming from the southern Ombai Strait. To confirm the above relation, we have calculated the correlation between zonal westward current at a depth of $\sim 100 \mathrm{~m}$ at point $\mathrm{B}_{\mathrm{EJ}}$ and that representing subsurface $(\sim 200 \mathrm{~m})$ maximum ITF in the southern Ombai Strait (Sprintall et al., 2010). The correlation coefficient between the zonal westward current at $\sim 100 \mathrm{~m}$ at the $\mathrm{B}_{\mathrm{EJ}}$ and that of the southern Ombai Strait is 0.58, with a $95 \%$ significance level of approximately \pm 0.33 . This study shows that the zonal westward current at $100 \mathrm{~m}$ depth at $\mathrm{B}_{\mathrm{EJ}}$ has a strong correlation with the subsurface $(\sim 200 \mathrm{~m})$ maximum ITF in the southern Ombai Strait, confirming that the ITF flowing from the Ombai Strait is the primary driver for zonal westward current at $\mathrm{B}_{\mathrm{EJ}}$.

In the offshore region of the study area, zonal current at $\mathrm{C}_{\mathrm{EJ}}$ (Fig. 6c and f) flows westward throughout the year and has average velocity around $0.20 \mathrm{~m} \mathrm{~s}^{-1}$ in the upper $100 \mathrm{~m}$. Under such characteristics, we propose that the westward current at this point is the SEC in the southeast Indian Ocean, which joins the ITF flowing out from the Lombok and Ombai straits and Timor Passage. The HYCOM westward current at this point is stronger during JJA than DJF, which is associated with seasonal characteristics of the ITF in Lombok Strait and Timor Passage and of the total ITF through the Lombok and Ombai straits and Timor Passage (Potemra, 1999; Sprint- all et al., 2009). The westward current at $\mathrm{C}_{\mathrm{EJ}}$ (Fig. 6c and f) reaches its maximum value of about $0.31 \mathrm{~m} \mathrm{~s}^{-1}$.

\subsubsection{Vertical structure of zonal current along the meridional section of West Java $\left(\mathrm{A}_{\mathrm{WJ}}-\mathrm{B}_{\mathrm{WJ}}-\mathrm{C}_{\mathrm{WJ}}\right)$}

Figure $6 \mathrm{~g}-1$ show the vertical structure of the zonal current along the meridional transect of West Java (WJ; $\mathrm{AWJ}_{\mathrm{WJ}^{-}}$ $\left.B_{\mathrm{WJ}}-\mathrm{C}_{\mathrm{WJ}}\right)$. Similar to $\mathrm{A}_{\mathrm{EJ}}$, mean zonal current at $A_{\mathrm{WJ}}$ (nearshore region) is attributed to the SJC, which generally flows eastward in the upper $100 \mathrm{~m}$ depth (Fig. $6 \mathrm{~g}$ and $\mathrm{j}$ ) and reaches a maximum value of about $0.12 \mathrm{~m} \mathrm{~s}^{-1}$. Our simulation shows that during the monsoon transitions (MAM and SON), SJC is eastward and intensified by the propagation of coastal Kelvin waves associated with the Wyrtki Jet in the equatorial Indian Ocean, which is forced by the local equatorial zonal winds during both monsoons. These waves propagate along the Sumatran and Javan coasts (i.e., Sprintall et al., 2000; Druskha et al., 2010; Iskandar et al., 2009) and some portions propagate northward into the Lombok and Makassar Straits (Susanto et al., 2000, 2012; Pujiana et al., 2013), whereas the remaining parts continue eastward (Syamsuddin et al., 2004). Furthermore, the present study shows that the eastward current during SON is stronger than that during MAM, which is consistent with mooring observation in the Makassar Strait (Susanto et al., 2012; their Fig. 3). The stronger eastward current during SON was supposed 


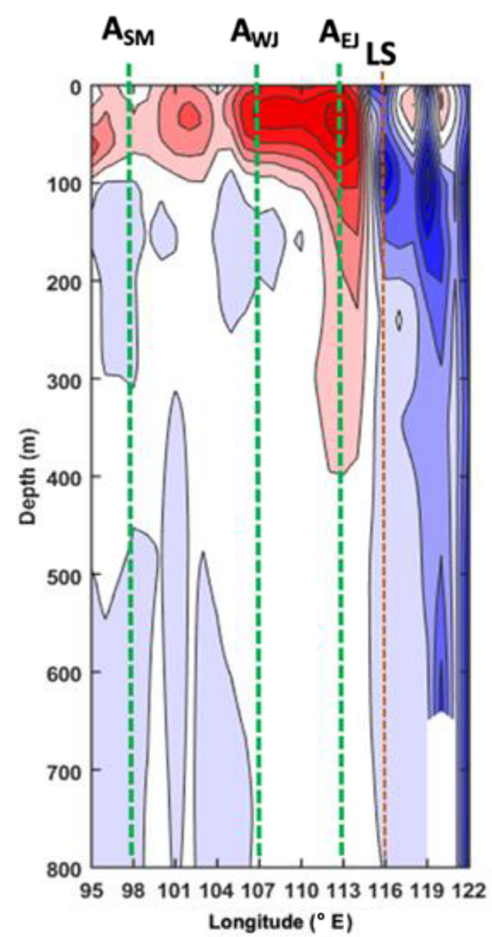

(a)

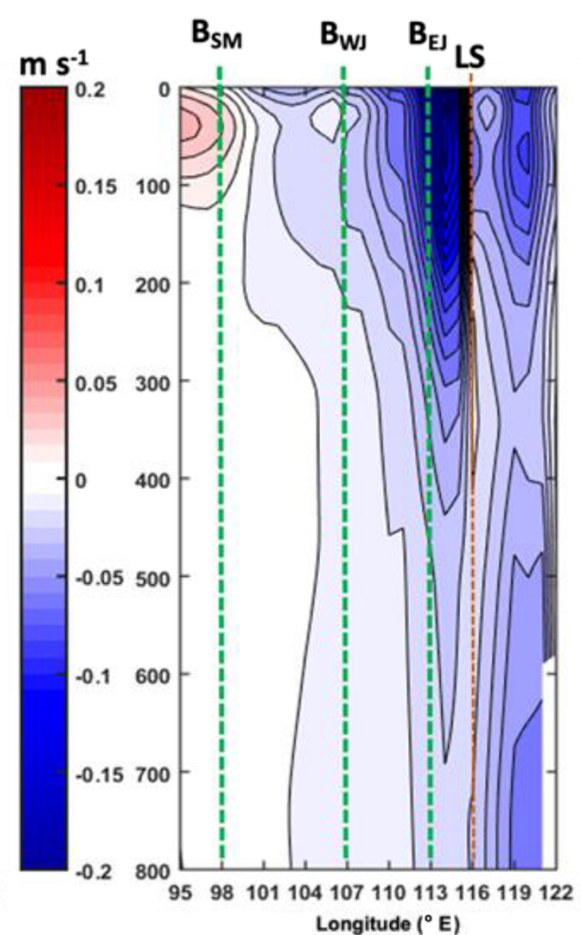

(b)

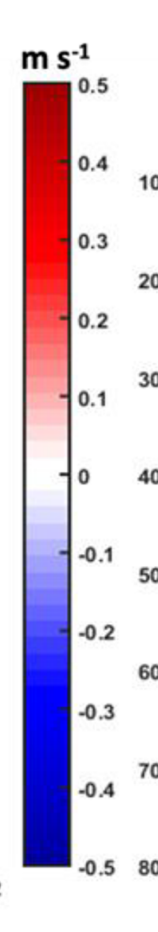

政

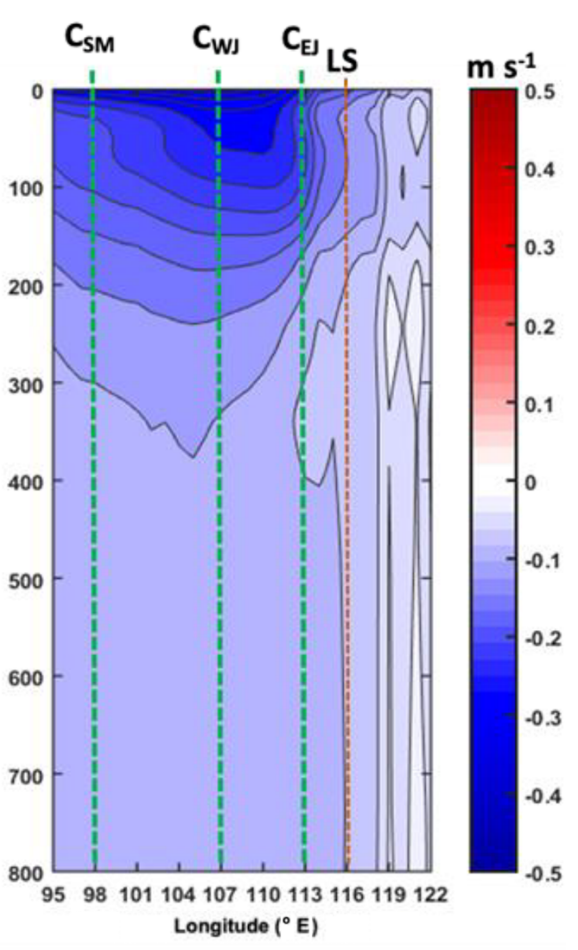

(c)

Figure 4. Longitude-depth profiles of mean zonal currents along (a) Transect A, (b) Transect B, and (c) Transect C. Positive (negative) values of the zonal currents indicate eastward (westward) currents. Dashed green lines denote the longitudes of the nine selected points, whereas the dashed orange line denotes the longitude of Lombok Strait (LS).

to be attributed to the faster and more intense climatological Wyrtki Jet during SON rather than during MAM (Knox, 1976; McPhaden, 1982; Han et al., 1999; Qiu et al., 2009; McPhaden et al., 2015; Figs. 1d and 2e of Duan et al., 2016) and also associated with stronger wind forcing over the eastern equatorial Indian Ocean during the SON period than the MAM period (figure not shown), which in turn causes the jet.

Moreover, it can be seen that during the NW monsoon the eastward current at $A_{W J}$ (Fig. $6 g$ and j) is weaker than that at $A_{E J}$ (Fig. 6a and d). The weaker current at $A_{W J}$ may exist as a consequence of the weaker mean $\mathrm{NW}$ monsoon at this point compared with that at $A_{E J}$ (Fig. 7). Interestingly, at a depth of $100 \mathrm{~m}$, there is a maximum westward current at $A_{W J}$ during DJF with velocity of about $0.1 \mathrm{~m} \mathrm{~s}^{-1}$ (Fig. $6 \mathrm{~g}$ and j). Here, we suggest that ITF is the cause of the westward current at $100 \mathrm{~m}$ at $\mathrm{A}_{\mathrm{WJ}}$ during the DJF. In regard to the ITF, Fig. 3 of Sprintall et al. (2010) shows cores of subsurface maximum ITF extending from 100 to $250 \mathrm{~m}$ depth in the northern part of the Ombai Strait and from 100 to $800 \mathrm{~m}$ depth at the southern part of the strait during DJF. Meanwhile, the influence of ITF on the zonal current at $\mathrm{A}_{\mathrm{EJ}}$ at $100 \mathrm{~m}$ is weaker as a consequence of the stronger NW monsoon at $\mathrm{A}_{\mathrm{EJ}}$ compared with that at $A_{W J}$ (Fig. 7), and thus the current instead flows eastward at $A_{E J}$ during DJF (Fig. 6a and d).
To further investigate which one is more influential out of the ITF and the NW monsoon in terms of forcing the zonal current at the $A_{W J}$ and $A_{E J}$ at $100 \mathrm{~m}$ depth, we have carried out correlations between the zonal current at both points (each at a depth of $\sim 100 \mathrm{~m}$ ) and both the NW zonal wind and the zonal current representing subsurface $(\sim 200 \mathrm{~m})$ maximum ITF in the southern Ombai Strait (Table 1). Here, the ITF in the southern part of the Ombai Strait was chosen for carrying out the correlations because the ITF mainly flows through the southern part of the passage (Sprintall et al., 2010). It was observed that the subsurface maximum ITF during DJF exists at a depth of about $200 \mathrm{~m}$ in both the northern and southern parts of the Ombai Strait and that it is stronger during DJF than JJA in both parts of the strait (Fig. 3 of Sprintall et al., 2010). In this study, the DJF zonal currents in the period of 2004 through 2006 in the southern Ombai Strait derived from the INSTANT program (http://www.marine.csiro.au/ cow074/instantdata.htm, last access: 17 May 2020) were used for the correlation analysis.

It is found that during DJF the zonal current at $A_{W J}$ at $100 \mathrm{~m}$ shows high correlation with the subsurface $(\sim 200 \mathrm{~m})$ maximum ITF in the southern Ombai Strait, whereas its correlation with the NW zonal wind is weak (Table 1). Moreover, although during DJF the correlations between the zonal 

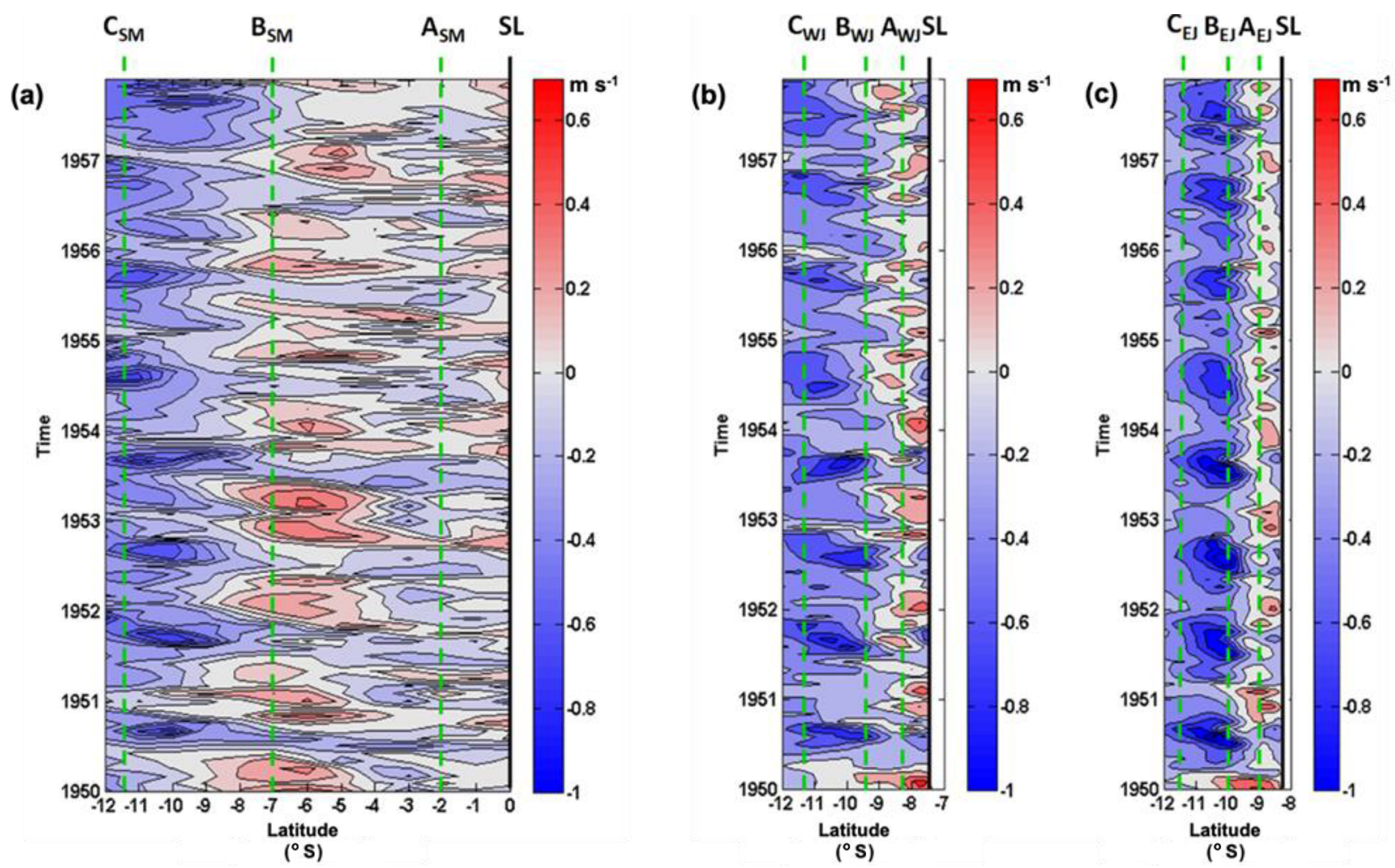

Figure 5. The zonal surface $(1 \mathrm{~m})$ currents along three meridional sections (yellow lines in Fig. 2): (a) SM (98 $\left.{ }^{\circ} \mathrm{E}\right)$, (b), WJ (107 $\left.{ }^{\circ} \mathrm{E}\right)$, and (c) EJ $\left(113^{\circ} \mathrm{E}\right)$. Positive (negative) values of the zonal currents indicate eastward (westward) currents. Meanwhile, dashed green lines denote the latitudes of the nine selected points. SL stands for shoreline.

Table 1. Correlation coefficients between zonal currents at $100 \mathrm{~m}$ depth at both $A_{W J}$ and $A_{E J}$ and both the local NW zonal wind and subsurface $(200 \mathrm{~m})$ maximum ITF in the southern Ombai Strait during DJF in the period of 2004 through 2006.

\begin{tabular}{lcr}
\hline Points & \multicolumn{2}{c}{ Correlation coefficients $(r)^{\mathrm{a}}$} \\
\cline { 2 - 3 } & $U$-SMITF & $U$-NWZW \\
\hline A & 0.76 & $-0.32^{\mathrm{b}}$ \\
$\mathrm{A}_{\mathrm{EJ}}$ & $-0.13^{\mathrm{b}}$ & $0.30^{\mathrm{b}}$ \\
\hline a The $95 \%$ significance level is approximately \\
$\pm 0.33 . U$ represents the zonal currents at $100 \mathrm{~m}$ \\
depth, SMITF stands for subsurface $(200 \mathrm{~m})$ \\
maximum ITF in the southern Ombai Strait, and \\
NWZW stands for northwesterly zonal wind. \\
b Correlation below the significance level.
\end{tabular}

current at $\mathrm{A}_{\mathrm{EJ}}$ at $100 \mathrm{~m}$ and both the NW zonal wind and the subsurface $(\sim 200 \mathrm{~m})$ maximum ITF in the southern Ombai Strait are below the significance level, the NW zonal wind is more influential regarding force variation of zonal current at $\mathrm{A}_{\mathrm{EJ}}$ at $100 \mathrm{~m}$ than the ITF. Hence, during DJF we suggest that the westward current simulated at $A_{W J}$ at $100 \mathrm{~m}$ is ITF related, whereas that at $\mathrm{A}_{\mathrm{EJ}}$ is relatively $\mathrm{NW}$ zonal wind re- lated. As already discussed, in addition to the local eastward winds during DJF, it is suggested that the arrival of downwelling Kelvin waves in December-January at $\mathrm{A}_{\mathrm{EJ}}$ may contribute to a net eastward current across the water column, which in turn reduces the influence of ITF at this point.

In the transition region, the mean current at $\mathrm{B}_{\mathrm{WJ}}$ is westward and is more dominated by the ITF (denoted by black lines in Fig. $6 \mathrm{~h}$ and $\mathrm{k}$ ). Similar to $\mathrm{B}_{\mathrm{EJ}}$, the seasonal feature of the subsurface maximum ITF is also found at $\mathrm{B}_{\mathrm{WJ}}$, where the corresponding westward current at this point reaches its maximum value at $\sim 100 \mathrm{~m}$ depth and is stronger during DJF than JJA (Fig. 6h and k). In this study, it is also found that the zonal westward current at $100 \mathrm{~m}$ depth at $\mathrm{B}_{\mathrm{WJ}}$ has a strong correlation with the subsurface $(\sim 200 \mathrm{~m})$ maximum ITF in the southern Ombai Strait, with a correlation coefficient of about 0.77 and a $95 \%$ significance level of approximately \pm 0.33 , corroborating that the ITF flowing from the Ombai Strait is the main driver for zonal westward current at this point.

Furthermore, like $\mathrm{C}_{\mathrm{EJ}}$, characteristics of persistent westward currents exist in the offshore region $\left(\mathrm{C}_{\mathrm{WJ}}\right)$, attributed to the SEC, and the westward current has a mean velocity of around $0.22-0.33 \mathrm{~m} \mathrm{~s}^{-1}$ in the upper $100 \mathrm{~m}$ (Fig. 6i and 1). 
(a)

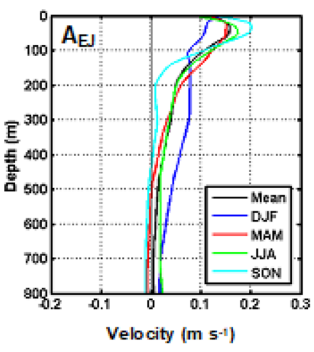

(d)

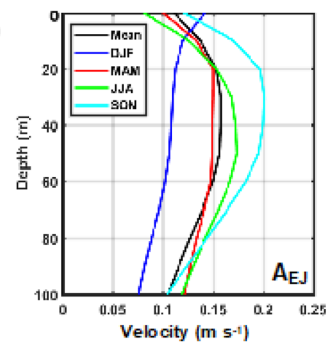

(g)

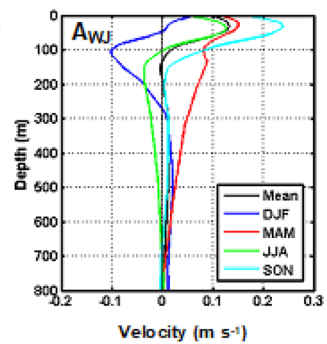

(j)

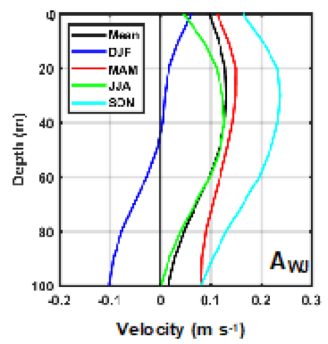

(m)

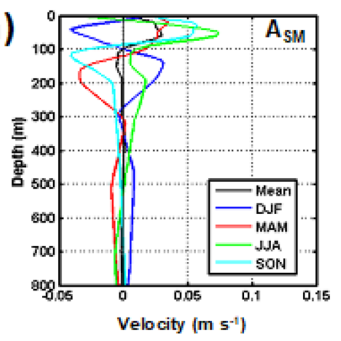

(p)

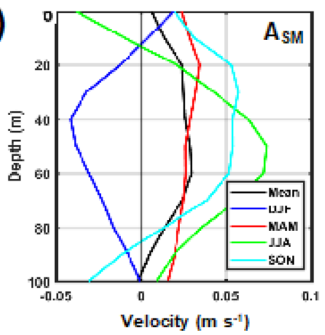

(b)

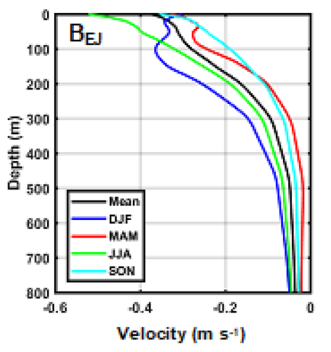

(e)

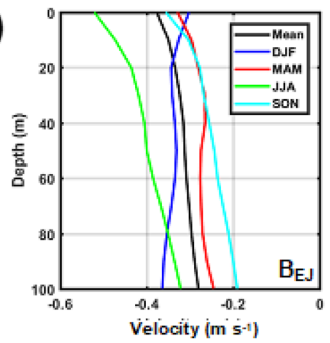

(h)

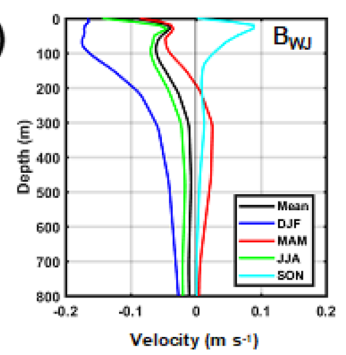

(k)

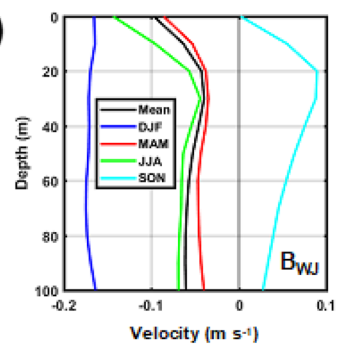

(n)

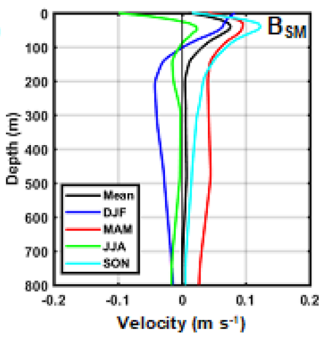

(q)

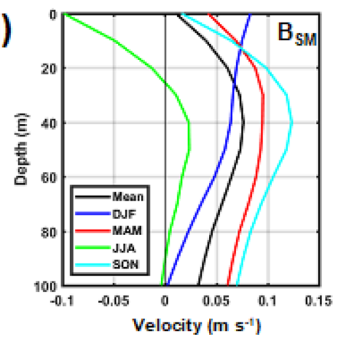

(c)

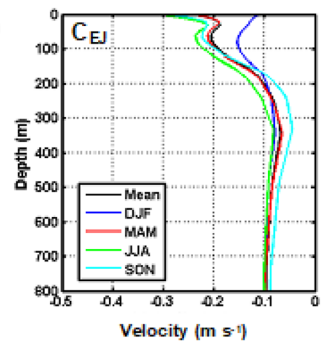

(f)

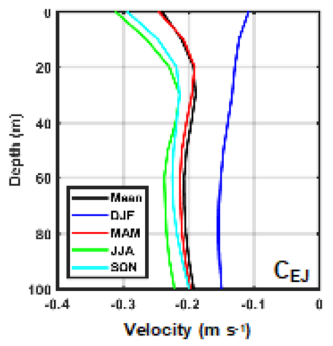

(i)

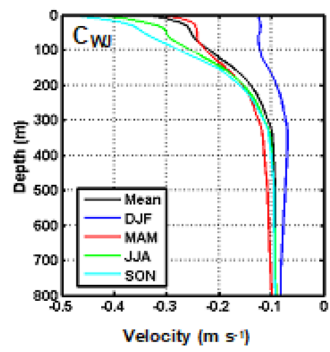

(I)

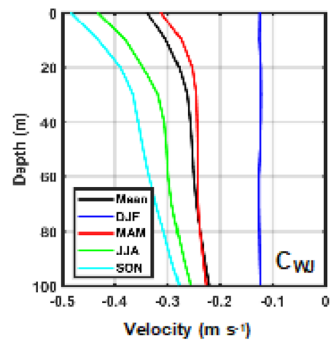

(o)

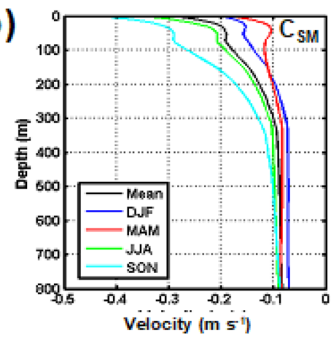

(r)

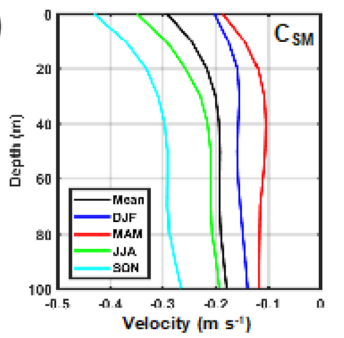

Figure 6. Mean and seasonal profiles of zonal current velocity derived from the HYCOM simulation results for the period of 1950 through 2013 at the following points: (a) $\mathrm{A}_{\mathrm{EJ}}$, (b) $\mathrm{B}_{\mathrm{EJ}}$, (c) $\mathrm{C}_{\mathrm{EJ}}$, (g) $\mathrm{A}_{\mathrm{WJ}}$, (h) $\mathrm{B}_{\mathrm{WJ}}$, (i) $\mathrm{C}_{\mathrm{WJ}}$, (m) $\mathrm{A}_{\mathrm{SM}}$, (n) $\mathrm{B}_{\mathrm{SM}}$, and (o) $\mathrm{C}_{\mathrm{SM}}$. Meanwhile, (d)-(f), (j)-(l), and (p)-(r) are the same as (a)-(c), (g)-(i), and (m)-(o), respectively, except provide results for depths of 0-100 $\mathrm{m}$. 


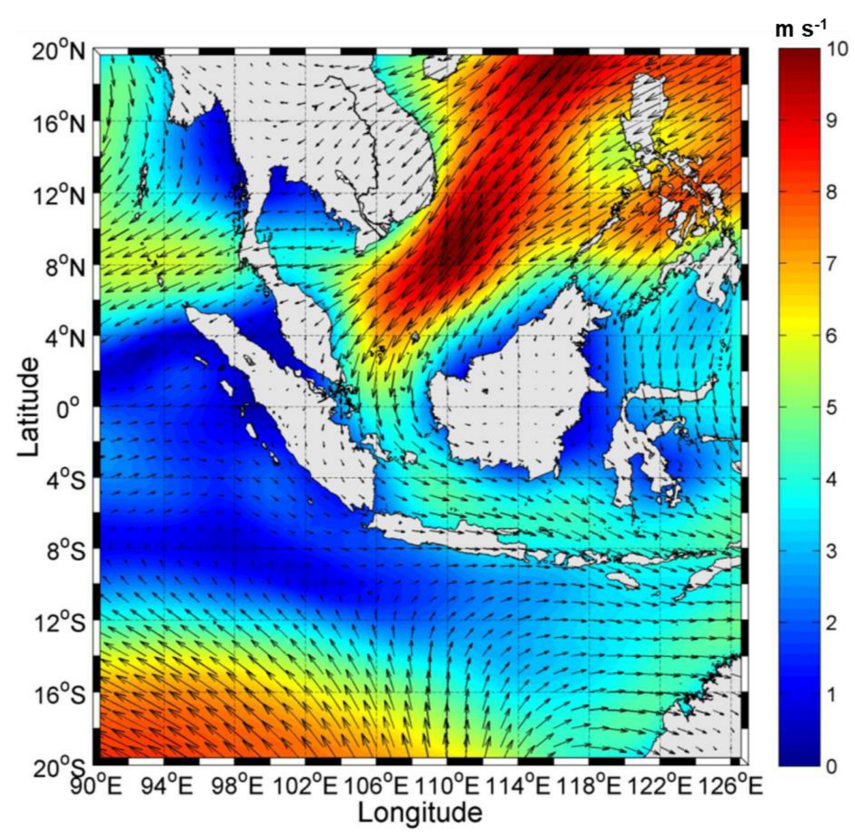

Figure 7. Mean NW monsoon for the period of 1950 to 2013 (climatological wind field during the DJF).

The simulated westward current at $\mathrm{C}_{\mathrm{WJ}}$ shows seasonal variations and reaches its maximum value at about $0.48 \mathrm{~m} \mathrm{~s}^{-1}$.

\subsubsection{Vertical structure of zonal current along the meridional section of Sumatra $\left(\mathrm{A}_{\mathrm{SM}}-\mathrm{B}_{\mathrm{SM}}-\mathrm{C}_{\mathrm{SM}}\right)$}

Vertical structures of zonal current along the meridional transect of Sumatra (SM; $\mathrm{A}_{\mathrm{SM}}-\mathrm{B}_{\mathrm{SM}}-\mathrm{C}_{\mathrm{SM}}$ ) are shown in Fig. $6 \mathrm{~m}-$ r. Similar to $A_{E J}$ and $A_{W J}$, mean zonal current at $A_{S M}$ (nearshore region) is eastward, attributed to SJC, and associated with the Kelvin wave propagation. However, due to A $_{S M}$ located in front of western Sumatra (Fig. 2) and oriented in the northwest-southeast direction, the meridional component of velocity at this point is also dominant (Figs. 1a and 2). Therefore, zonal currents at $A_{S M}$ are relatively weak compared to those at $A_{W J}$ and $A_{E J}$, which are located in front of southern Java and oriented in the west-east direction. For example, during SON, the eastward current reaches its maximum velocity of about $0.05 \mathrm{~m} \mathrm{~s}^{-1}$ at $\mathrm{A}_{\mathrm{SM}}$ (cyan lines in Fig. $6 \mathrm{~m}$ and p), whereas it is about $0.23 \mathrm{~m} \mathrm{~s}^{-1}$ (at $\mathrm{A}_{\mathrm{WJ}}$; Fig. $6 \mathrm{~g}$ and j) and $0.20 \mathrm{~m} \mathrm{~s}^{-1}$ (at $\mathrm{A}_{\mathrm{EJ}}$; Fig. $6 \mathrm{a}$ and d) at $\sim 30$ $50 \mathrm{~m}$ depth.

Furthermore, results of this study show that a maximum value of the eastward current at $A_{S M}, A_{W J}$, and $A_{E J}$ is found at a certain depth (at $\sim 30-50 \mathrm{~m}$ depth), and this strengthening of eastward flows is supposed to be attributed to a baroclinic Kelvin wave. The baroclinic Kelvin wave propagating vertically and horizontally along its waveguide can exert the most energy at a certain depth (Drushka et al., 2010; Pujiana et al., 2013; Iskandar et al., 2014). According to laboratory experiment observations conducted by Codiga et al. (1999) and Hallock et al. (2009), Kelvin waves can be trapped in a slope and propagate along an isobath. This phenomenon is known as a slope-trapped baroclinic Kelvin wave. Moreover, Kelvin waves that propagate along continental slope with strong stratification can cause strong current velocity. Codiga et al. (1999) also found that this slope Kelvin wave is formed after encountering a canyon-like bathymetry. Meanwhile, Pujiana et al. (2013) showed that Kelvin wave propagation from Lombok Strait to Makassar Strait, across the Sunda continental slope, is along isobaths at depths greater than $50 \mathrm{~m}$. In this present study, the eastward current along the Transect $A$ has a maximum current velocity at $\sim 30-50 \mathrm{~m}$ depth. Therefore, it is suggested that this maximum eastward current at $\sim 30-50 \mathrm{~m}$ depth is associated with a slope-trapped Kelvin wave that propagates at that depth along the southern coasts of Sumatra and Java.

In the transition region, the characteristics of the average zonal current (the climatological current field) at $\mathrm{B}_{\mathrm{SM}}$ (Fig. 6n and q) are different from those at $\mathrm{B}_{\mathrm{WJ}}$ (Fig. 6h and $\mathrm{k}$ ) and $\mathrm{B}_{\mathrm{EJ}}$ (Fig. $6 \mathrm{~b}$ and e). The average current at $\mathrm{B}_{\mathrm{SM}}$ is eastward, while at points $\mathrm{B}_{\mathrm{WJ}}$ and $\mathrm{B}_{\mathrm{EJ}}$ it is westward. During NW and transitional periods of the monsoon, zonal current at $\mathrm{B}_{\mathrm{SM}}$ flows eastward and reaches its maximum velocity of about $0.12 \mathrm{~m} \mathrm{~s}^{-1}$ at a depth of $40 \mathrm{~m}$ within the period of SON (Fig. 6q). Meanwhile, during the SE monsoon, the zonal current at this point flows westward. In contrast to the mean zonal currents in the nearshore region $\left(\mathrm{A}_{S M}\right)$, it seems that the average zonal current field at $\mathrm{B}_{\mathrm{SM}}$ is not attributed to SJC. The reason is the $\mathrm{B}_{\mathrm{SM}}$ location, which is far from the coasts of Mentawai Islands and Enggano Island off the western coast of Sumatra ( $430 \mathrm{~km}$ away). This distance is more than Rossby radius of deformation at this latitude $(\sim 90 \mathrm{~km})$. Thereby, Kelvin waves, which affect the SJC variations, do not exist at this point. We suggest that the current variability at $\mathrm{B}_{\mathrm{SM}}$ is influenced by tropical current systems in the Indian Ocean, such as the Equatorial Counter Current (ECC), Southwest Monsoon Current (SWMC), and Wyrtki Jet. Here, we displayed seasonal averaged surface currents over 64 years (1950-2013) and schematics of the tropical current systems in the Indian Ocean as supporting evidence (Fig. 8).

Figure 8 shows that $\mathrm{B}_{\mathrm{SM}}$ is located in an area that is affected by the ECC, SWMC, and Wyrtki Jet. It can be seen in Fig. 8a that during DJF surface currents along the equatorial Indian Ocean are dominated by the westward North Equatorial Current (NEC) and the eastward ECC. Meanwhile, during JJA (Fig. 8c) the NEC disappears and the ECC becomes absorbed into the SWMC, which dominantly flows eastward in the northern Indian Ocean (Tomczak and Godfrey, 1994). In addition, during the transitional periods (MAM and SON) the jet is generated and causes a strengthening of eastward flows along the equatorial Indian Ocean (Fig. 8b and d). This explains why the climatological current at $\mathrm{B}_{\mathrm{SM}}$ flows eastward and reaches its maximum velocity during SON and MAM. These currents (the ECC, SWMC, and Wyrtki Jet) 

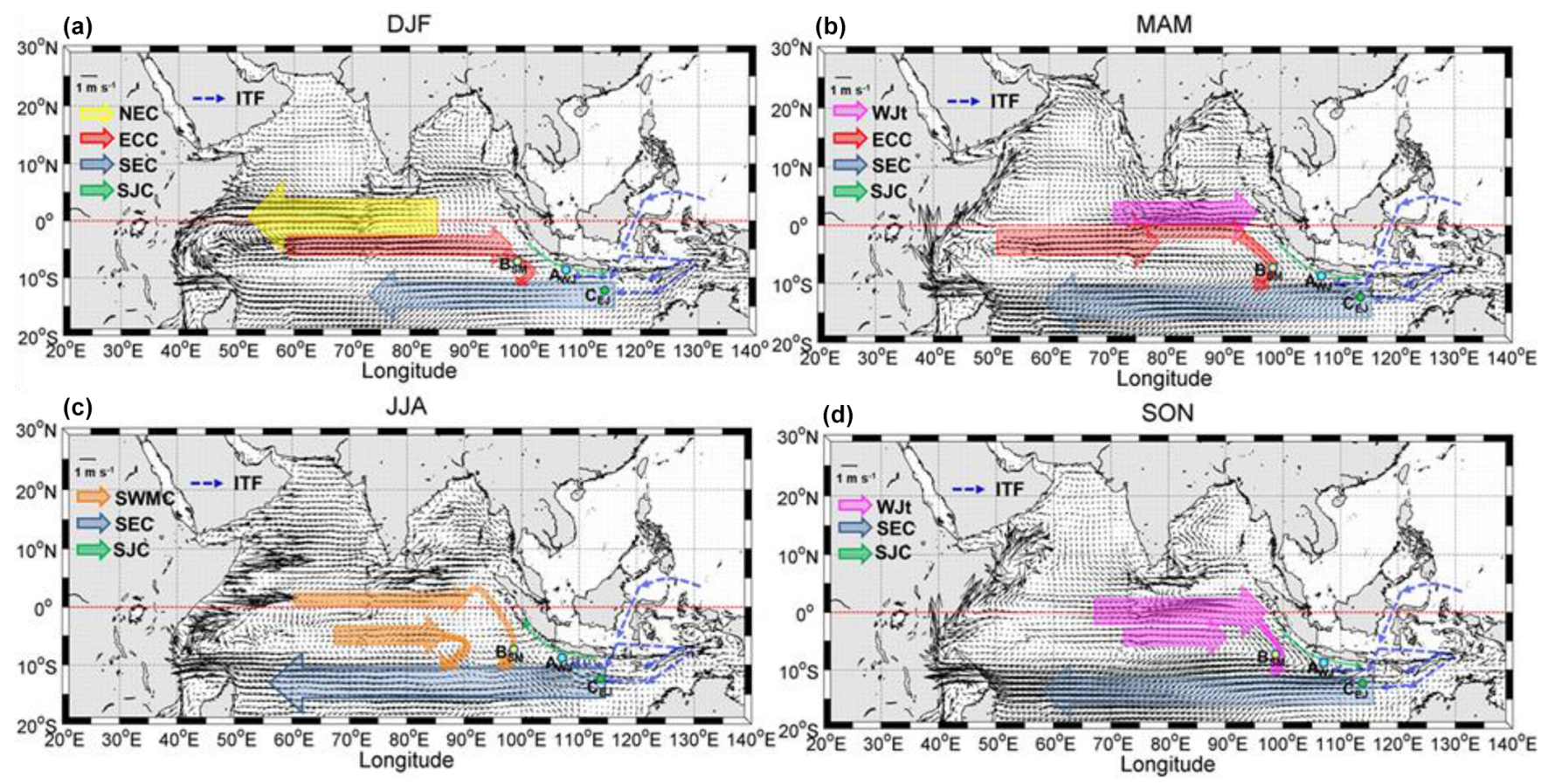

Figure 8. Seasonal averaged surface $(1 \mathrm{~m})$ currents over 64 years (1950-2013) and schematics of the tropical current systems in the Indian Ocean during (a) DJF, (b) MAM, (c) JJA, and (d) SON. Current branches indicated by coloured arrows (not black) are the North Equatorial Current (NEC), Equatorial Counter Current (ECC), South Equatorial Current (SEC), South Java Current (SJC), Wyrtki Jet (WJt), Southwest Monsoon Current (SWMC), and Indonesian Throughflow (ITF). The dashed line represents the thermocline current.

flow eastward before they turn and some part of their flow feed into the SEC in the southern Indian Ocean.

Current characteristics in the offshore region $\left(\mathrm{C}_{\mathrm{SM}}\right)$ generally show similarities with those at $\mathrm{C}_{\mathrm{WJ}}$ and $\mathrm{C}_{\mathrm{EJ}}$, as shown in Fig. 60 and r. The current at $\mathrm{C}_{\mathrm{SM}}$ is attributed to the SEC and flows westward year round, with a mean velocity around $0.18-0.3 \mathrm{~m} \mathrm{~s}^{-1}$ in the upper $100 \mathrm{~m}$. In addition, the strength of westward current at $\mathrm{C}_{\mathrm{SM}}$ varies seasonally and reaches its maximum value of about $0.42 \mathrm{~m} \mathrm{~s}^{-1}$ during SON (Fig. 6r).

\subsection{Zonal current variability}

EOF analysis gives vertical mode structures (spatial mode) and their normalized temporal mode variabilities relative to the mean which influence zonal current variability in the study area. Before performing the EOF analysis, the average value of the current data has been removed (solid black lines in the Fig. 6a-r). To further analyze the zonal current characteristics in the nearshore and offshore areas and the transition region between them, we examined the EOF modes of zonal current across the three meridional sections (EJ, WJ, and SM). In this paper, we only considered the first mode of EOF (EOF1) analysis since it is associated with the largest percentage of the variance. Figure 9 shows vertical structures and their associated temporal variability of EOF1 of zonal currents along the meridional sections. Here, as an example, the temporal variability is only shown for the last 8 - year period of the EOF1 (2006-2013). It can be clearly seen that remarkable features of zonal currents are revealed between nearshore and offshore areas in the three meridional sections (Fig. 9).

In general, the temporal mode of EOF1 of zonal currents across each meridional section shows intraseasonal and semiannual variabilities both in the nearshore and transition regions, whereas annual and interannual variations exist in the offshore area. However, the vertical structures of EOF1 in each section are quite different. In the nearshore area of Section EJ (Fig. 9a), the vertical structure of EOF1 is characterized by one-layer flow with a gradual decrease in speed from the surface to $800 \mathrm{~m}$ depth, whereas in the transition and the offshore regions the flow velocities decrease more rapidly with depth until they become nearly zero at depths of about 500 and $300 \mathrm{~m}$, respectively. Meanwhile, in Section WJ (Fig. 9c) the vertical structure of EOF1 is also characterized by one-layer flow in which its unidirectional vertical structure gradually decreases from the surface to a depth of about $450 \mathrm{~m}$ in all areas. In contrast, a different vertical structure of EOF1 appears in Section SM (Fig. 9e). In this section, the vertical structure is characterized by two-layer flow in the nearshore and transition regions with the changeover between the two types of flow occurring at a depth of about 100 and $200 \mathrm{~m}$, respectively. In addition, in the offshore area of Section SM, the vertical structure of EOF1 displays a unidirectional flow from the surface to a depth of $\sim 500 \mathrm{~m}$. 


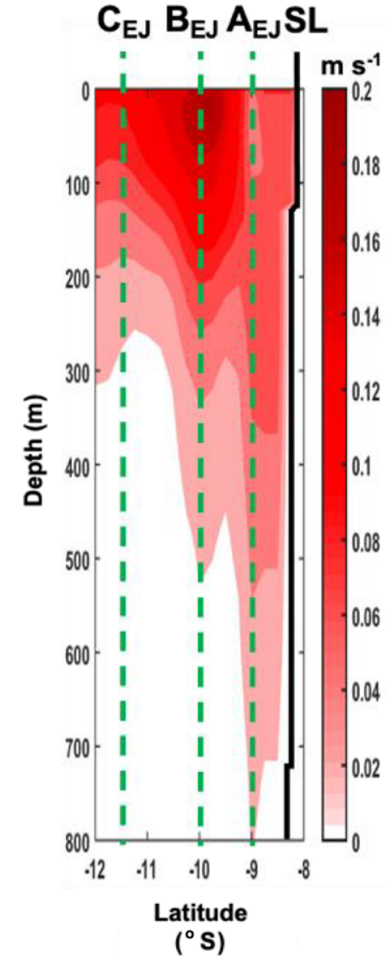

(a)

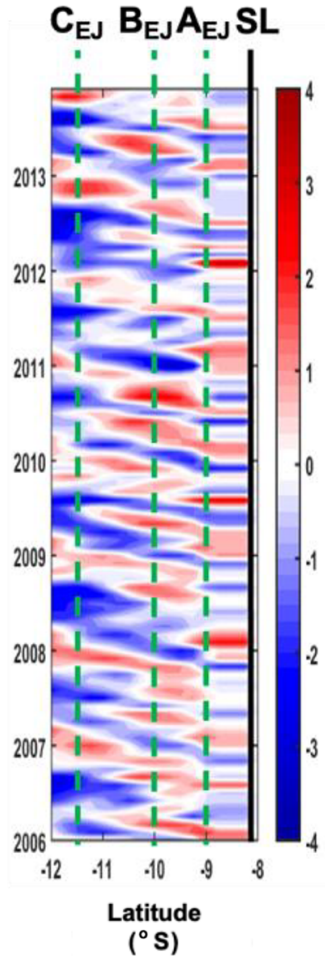

(b)

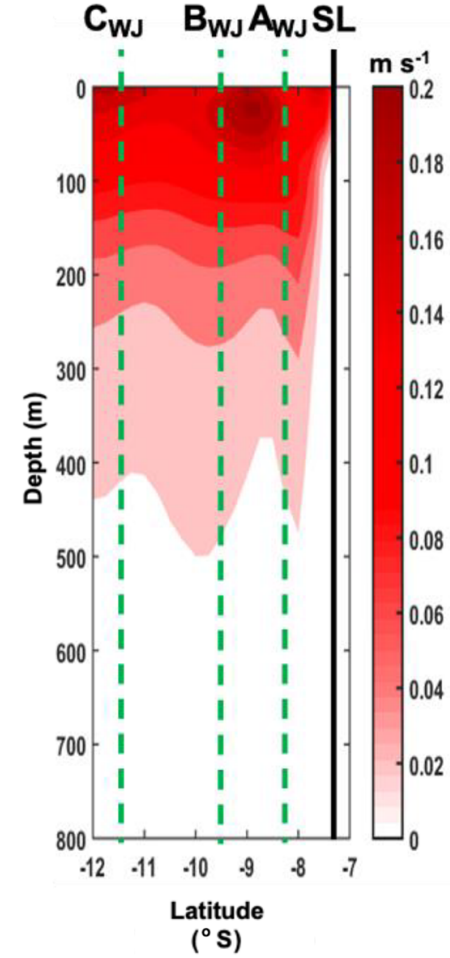

(c)

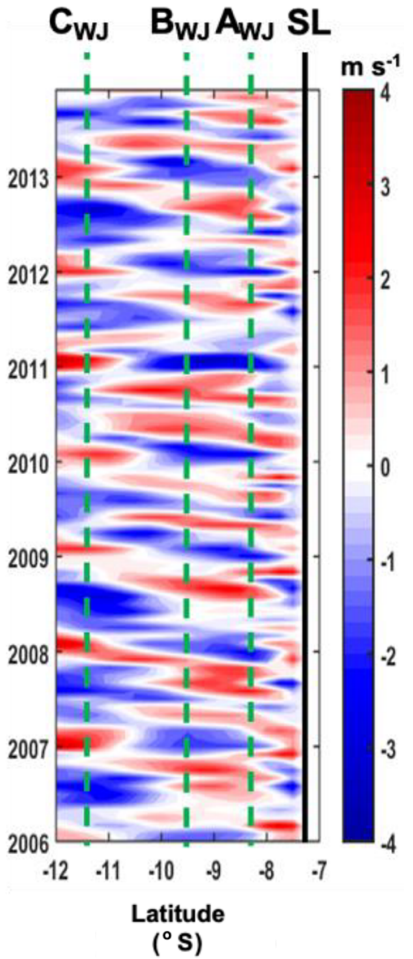

(d)

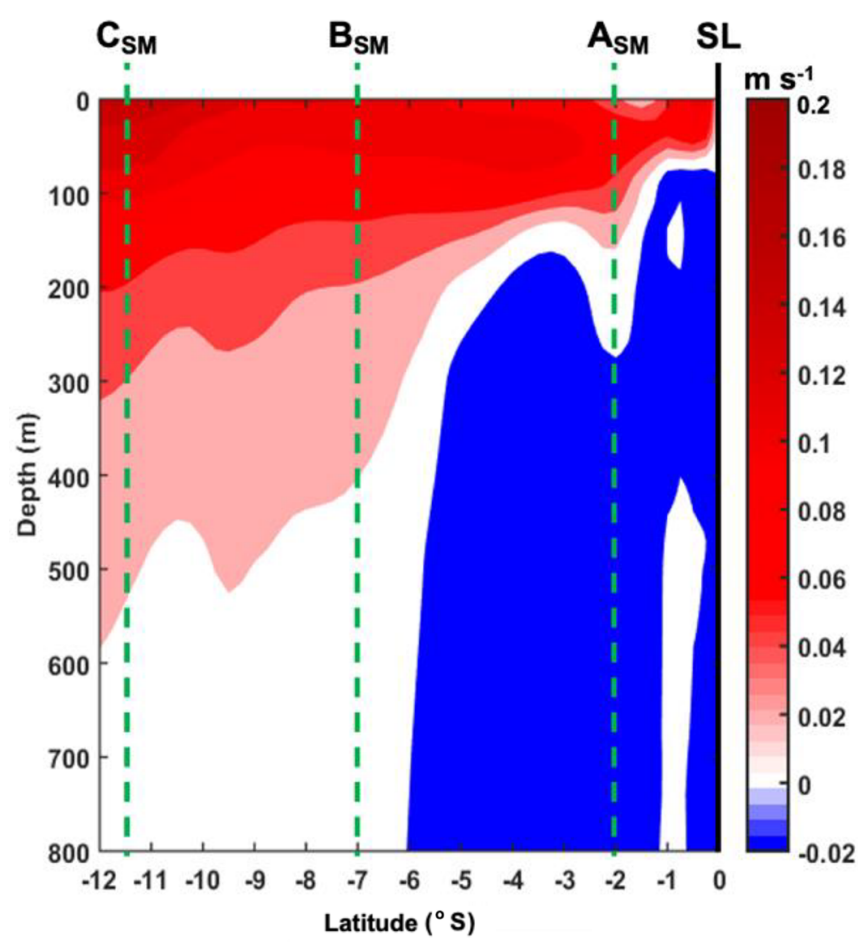

(e)

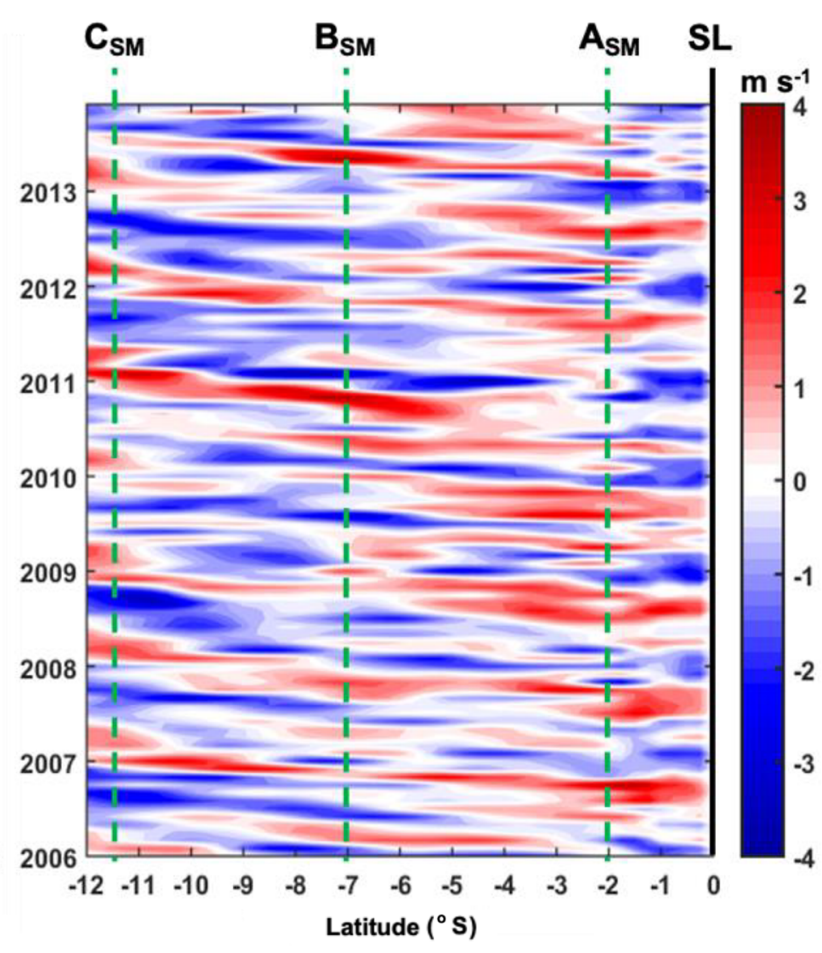

(f)

Figure 9. Vertical mode structures $(\mathbf{a}, \mathbf{c}, \mathbf{e})$ and their associated temporal variability of EOF1 (b, d, f) for zonal currents relative to the mean flow along the three meridional sections: $\mathrm{EJ}(\mathbf{a}, \mathbf{b}), \mathrm{WJ}(\mathbf{c}, \mathbf{d})$, and SM $(\mathbf{e}, \mathbf{f})$. In this case, the temporal variability is shown for the last 8-year period of the EOF1. The direction of mode velocities relative to the mean flow is determined by multiplying the sign of the vertical mode structure and the sign of the temporal mode variability. Positive (negative) values of the velocity variability relative to the mean flow indicate eastward (westward) flow. Meanwhile, dashed green lines indicate the latitudes of the nine analyzed points, and SL stands for shoreline. 
To examine the EOF modes of zonal currents in more detail, further analysis was performed at three points on each meridional transect, namely points $\mathrm{A}_{\mathrm{EJ}}, \mathrm{B}_{\mathrm{EJ}}$, and $\mathrm{C}_{\mathrm{EJ}}$ (Transect $\mathrm{EJ}$ ); points $\mathrm{A}_{\mathrm{WJ}}, \mathrm{B}_{\mathrm{WJ}}$, and $\mathrm{C}_{\mathrm{WJ}}$ (Transect $\mathrm{WJ}$ ); and points $\mathrm{A}_{\mathrm{SM}}, \mathrm{B}_{\mathrm{SM}}$, and $\mathrm{C}_{\mathrm{SM}}$ (Transect $\mathrm{SM}$ ). Table 2 displays the dominant variances at those points. As can be seen in Table 2, the first three modes at each point (except $\mathrm{A}_{\mathrm{SM}}$ ) already represent $\geq 95 \%$ of the total variance. In fact, the first two modes at each point (except $\mathrm{A}_{\mathrm{SM}}$ and $\mathrm{A}_{\mathrm{EJ}}$ ) already represent $\geq 91 \%$ of the total variance.

Here, we only consider the first modes of EOF analysis for further analysis since their percent variances (except at point $\mathrm{A}_{\mathrm{SM}}$ ) are more than $50 \%$ of the total variance (Table 2). Since the temporal variability of the EOF1 contains more than one frequency (Fig. 9b, d, and f), to find out what frequencies are dominant in the EOF1 it was then analyzed by using the EEMD method to decompose the signal. In this study, the EEMD analyses of currents are only presented at one point on each meridional transect, namely AWJ (Transect $\mathrm{WJ}$ ), $\mathrm{B}_{\mathrm{SM}}$ (Transect $\mathrm{SM}$ ), and $\mathrm{C}_{\mathrm{EJ}}$ (Transect EJ). The $A_{W J}, B_{S M}$, and $C_{E J}$ points were chosen to investigate SJC variability, interannual variability in the open SETIO, and SEC and ITF variabilities, respectively.

The EEMD analysis of the first temporal EOF mode provides 10 modes and signals, of which the first signal of the EEMD result is the summation of the second to tenth signals, which is in turn the same as the original EOF first temporal mode of zonal currents. Meanwhile, the second-sixth signals of the EEMD result vary from intraseasonal to interannual variabilities. The remaining signals of EEMD result show the long-term variation and trend. Moreover, the proportion of contribution of each EEMD mode to the EOF1 is estimated by calculating standard deviation of each EEMD mode relative to the total variance of PC1 (Figs. 10-12). In general, the contributions of each EEMD mode to the EOF1 at $\mathrm{A}_{\mathrm{WJ}}$ and $\mathrm{B}_{\mathrm{SM}}$, from largest to smallest, are intraseasonal, semiannual, annual, interannual, and long-term (Figs. 10 and 11). Intriguingly, however, the contribution of long-term signal $(19.2 \%)$ at $\mathrm{C}_{\mathrm{EJ}}$ is larger than the interannual $(16.3 \%)$ and annual (14.7\%) signals (Fig. 12). For the scope of this paper, we only focused on the analysis of the EOF1 of zonal current from intraseasonal to interannual timescales. The interesting results concerning the existence of pronounced contribution of long-term variation to the EOF1 at $\mathrm{C}_{\mathrm{EJ}}$ will be investigated in a future study.

\subsubsection{Intraseasonal, semiannual, and annual variations}

Figure $10 \mathrm{a}-\mathrm{b}$ show the vertical structure and temporal variability of the EOF1 (58\% of total variance) at AWJ, respectively. In order to see the temporal variation of the EOF1 more clearly in Fig. 10b, we have also provided data for the last 8-year period of the EOF first temporal mode (Fig. 10c, as an example). Current velocity variability relative to the mean flow can be obtained by multiplying the vertical mode structure (Fig. 10a) with the temporal variability (Fig. 10b).

Intraseasonal, semiannual, and annual variabilities of the EOF first temporal mode at $A_{W J}$ as a result of the EEMD analysis are displayed in Fig. 10d-f, where their power spectra (Fig 10, left column) show the maximum energy for 3month, 6-month, and 12-month periods, respectively. At this point, the highest power spectrum occurs at semiannual variability (Fig. 10e). In this figure (right), the semiannual variability of the EOF first temporal mode at AWJ clearly shows the presence of an eastward anomaly of the zonal current during the MAM and SON, which may be enhanced by downwelling Kelvin waves associated with the Wyrtki Jet in the equatorial Indian Ocean. Meanwhile, the anomaly of the zonal current at $A_{W J}$ is westward during JJA in response to the prevailing southeasterly local winds during the SE monsoon. On the other hand, during DJF the anomaly of the zonal current at $A_{W J}$ is not associated with the prevailing northwesterly local winds during the NW monsoon, in which the current anomaly is westward during this monsoon (Fig. 10e). As already discussed in Sect. 3.2 (Table 1 and Fig. 7), this may be attributed to the ITF, which has more influence on variation of zonal current at $\mathrm{AWJ}_{\mathrm{WJ}}$ during DJF than the NW local wind.

Similar to $A_{W J}$, the first mode of EOF vertical structure and its temporal variability (64\% of total variance) at $\mathrm{B}_{\mathrm{SM}}$ show seasonal pattern (Fig. 11a-c). It is also found that signal on a 6-month (semiannual) period is quite dominant at $\mathrm{B}_{\mathrm{SM}}$ (Fig. 11e). In order to see the seasonal variation more clearly, we have provided a probability distribution function of the EOF1 of zonal currents for the NW, SE, and transition seasons at $\mathrm{B}_{\mathrm{SM}}$ at a depth of $\sim 40 \mathrm{~m}$ (Fig. 14). The $40 \mathrm{~m}$ depth was selected as an example because the most obvious seasonal variation of currents is present at this depth. It is found that variation of zonal current at $\mathrm{B}_{\mathrm{SM}}$ is dominantly eastward during DJF (Fig. 14a) and that this eastward current is enhanced during MAM and SON (Fig. 14b and d), which may be attributed to the tropical current systems in the Indian Ocean (ECC, SWMC, and Wyrtki Jet). Meanwhile, during JJA (Fig. 14c) the dominance of eastward current reduces, and the current tends to be dominantly westward. Furthermore, Fig. 12a-c show the first mode of EOF vertical structure and its temporal variability ( $72 \%$ of total variance) at $\mathrm{C}_{\mathrm{EJ}}$. In general, the anomaly of the zonal current at $\mathrm{C}_{\mathrm{EJ}}$ is westward, which is supposed to be associated with the meeting of SEC driven by trade winds and the ITF at this region. The EEMD analysis of the EOF1 of zonal current at $\mathrm{C}_{\mathrm{EJ}}$ also shows intraseasonal-interannual variabilities (Fig. 12d$\mathrm{g}$ ), where it is found that interannual timescale dominates the zonal current variation at $\mathrm{C}_{\mathrm{EJ}}(0.017$ power per year).

To obtain a better understanding of the zonal current characteristics at $\mathrm{A}_{\mathrm{WJ}}, \mathrm{B}_{\mathrm{SM}}$, and $\mathrm{C}_{\mathrm{EJ}}$, we have summarized the maximum energy density of zonal currents at intraseasonal, semiannual, annual, and interannual timescales that exists at each point based on power spectrum calculation in Figs. 10- 
Table 2. Dominant variances at the nine observation points.

\begin{tabular}{lrrr|rrr|rrr}
\hline Mode & \multicolumn{10}{c}{ Variance (\%) } \\
\cline { 2 - 10 } & \multicolumn{2}{c|}{ Section EJ } & \multicolumn{3}{|c|}{ Section WJ } & \multicolumn{3}{|c}{ Section SM } \\
\cline { 2 - 10 } & $\mathrm{A}_{\mathrm{EJ}}$ & $\mathrm{B}_{\mathrm{EJ}}$ & $\mathrm{C}_{\mathrm{EJ}}$ & $\mathrm{A}_{\mathrm{WJ}}$ & $\mathrm{B}_{\mathrm{WJ}}$ & $\mathrm{C}_{\mathrm{WJ}}$ & $\mathrm{A}_{\mathrm{SM}}$ & $\mathrm{B}_{\mathrm{SM}}$ & $\mathrm{C}_{\mathrm{SM}}$ \\
\hline 1 & 60 & 76 & 72 & 58 & 84 & 87 & 37 & 64 & 88 \\
2 & 29 & 18 & 20 & 33 & 12 & 10 & 25 & 27 & 9 \\
3 & 6 & 4 & 3 & 5 & & & 13 & 6 & \\
4 & & & 2 & & & & 10 & & \\
5 & & & & & & & 6 & & \\
6 & & & & & & & 4 & & \\
\hline Total & 95 & 98 & 97 & 96 & 96 & 97 & 95 & 97 & 97 \\
\hline
\end{tabular}

Table 3. Maximum energy density (peak energies) at intraseasonal, semiannual, annual, and interannual timescales at points $\mathrm{A}_{\mathrm{WJ}}$, $\mathrm{B}_{\mathrm{SM}}$, and $\mathrm{C}_{\mathrm{EJ}}$.

\begin{tabular}{lrrrr}
\hline \multirow{2}{*}{ Points } & \multicolumn{4}{c}{ Maximum energy density (peak period) } \\
\cline { 2 - 5 } & IS & SA & AN & IA \\
\hline A $_{\text {WJ }}$ & $0.070(3.0)$ & $0.140(6.0)$ & $0.038(12.0)$ & $0.003(36.0)$ \\
B $_{\text {SM }}$ & $0.015(3.0)$ & $0.135(6.0)$ & $0.007(12.0)$ & $0.012(36.0)$ \\
C $_{\text {EJ }}$ & $0.012(2.0)$ & $0.008(6.6)$ & $0.012(12.0)$ & $0.017(44.4)$ \\
\hline
\end{tabular}

IS stands for intraseasonal, SA stands for semiannual, AN stands for annual, and IA stands for interannual. Maximum energy density is given in power per year, and the peak periods are given in months.

12 (Table 3). It is shown that the zonal currents at $A_{W J}$ have peak energies that are consecutively dominated by semiannual, intraseasonal, and annual signals, while the interannual signal is weaker than them at this point. Furthermore, although semiannual and intraseasonal signals are dominant at $\mathrm{B}_{\mathrm{SM}}$, there is pronounced interannual variation of the zonal current at this point. In contrast, the zonal current variability at $\mathrm{C}_{\mathrm{EJ}}$ is dominated by interannual signal.

Furthermore, based on the power spectrum calculation shown in Fig. 12 (Table 3), it is found that intraseasonal variability of the SEC (zonal current at $\mathrm{C}_{\mathrm{EJ}}$ ) is also prominent $(\sim 0.012$ power per year $)$ in addition to the interannual signal $(\sim 0.017$ power per year). Meanwhile, based on sea level anomaly data in the period of October 1992 to the end of 1998 (about 6 years), Feng and Wijffels (2002) suggested that the strongest intraseasonal variability in the SETIO occurs in the SEC during the July-September season with baroclinic instability seeming to be the leading cause. On the other hand, in this study we found that the strongest intraseasonal variability occurs in the SJC (zonal current at $A_{W J}$ ). This different result seems to be due to differences in the length of data used in this study (64 years) and that in Feng and Wijffels (2002) (6 years). In addition, in this study we analyzed intraseasonal variability from the signal of the EOF first temporal mode of zonal currents (accounting for $58 \%, 64 \%$, and $72 \%$ of total variance at $\mathrm{A}_{\mathrm{WJ}}, \mathrm{B}_{\mathrm{SM}}$, and $\mathrm{C}_{\mathrm{EJ}}$, respectively), whereas Feng and Wijf- fels (2002) analyzed the intraseasonal variation from standard deviation of the 6-year sea level anomaly data based on the $100 \mathrm{~d}$ high-pass filtered altimeter data during the four seasons (January-March, April-June, July-September, and October-December). Moreover, some of the differences may also be due to the fact that altimeter data do not resolve coastal processes well. However, further study is required to address this issue.

\subsubsection{Interannual variations}

In this study, it is found that the most energetic zonal current variations of EOF1 at $\mathrm{A}_{\mathrm{WJ}}, \mathrm{B}_{\mathrm{SM}}$, and $\mathrm{C}_{\mathrm{EJ}}$ exist at $\sim 30 \mathrm{~m}$ depth (Figs. 10a, 11a, and 12a). To exclusively investigate the ocean currents at an interannual timescale, lagged correlation analyses have been applied between the zonal currents at a depth of about $30 \mathrm{~m}$ at points $\mathrm{A}_{\mathrm{WJ}}, \mathrm{B}_{\mathrm{SM}}$, and $\mathrm{C}_{\mathrm{EJ}}$ and each of the climatic indices (e.g., ONI and DMI), as shown in Table 4. The ONI and DMI indices from 1950 to 2013 used in this study are shown in Fig. 13.

The analysis of the lagged correlation indicates that the currents at $\mathrm{B}_{\mathrm{SM}}$ and $\mathrm{C}_{\mathrm{EJ}}$ show positive correlations with the ONI, namely $r(18)=0.24$ and $r(4)=0.27$, respectively, with the $95 \%$ significance level approximately \pm 0.07 , indicating that an El Niño (La Niña) event is favorable for an eastward (westward) currents at these points (Figs. 11g and $12 \mathrm{~g}$ ) and showing that ITF transport is lower (higher) during 

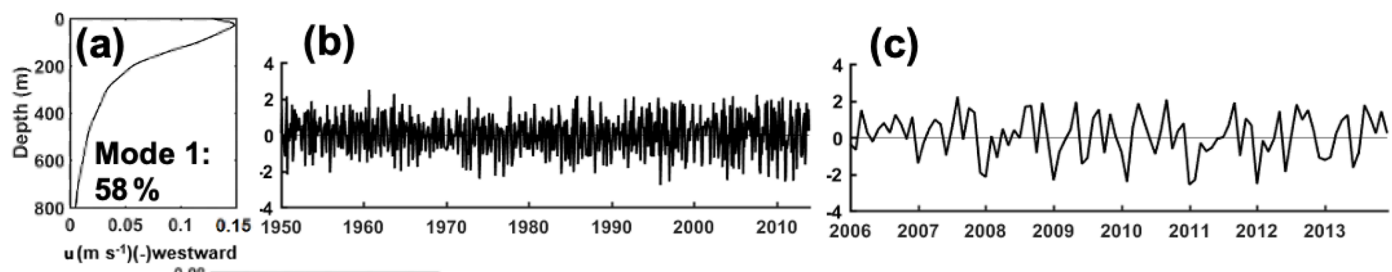

(d)
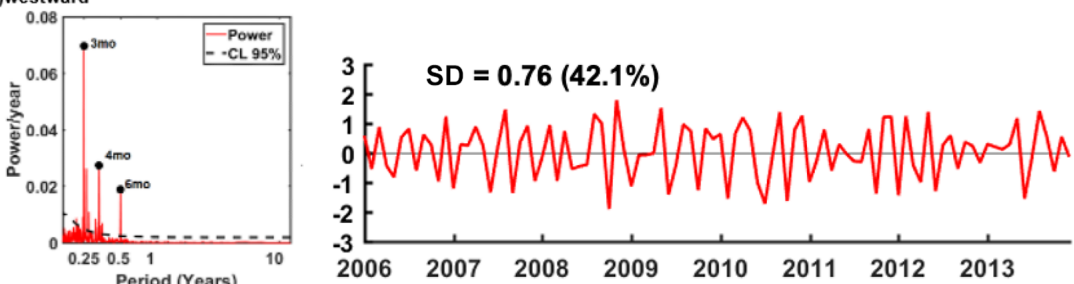

(e)
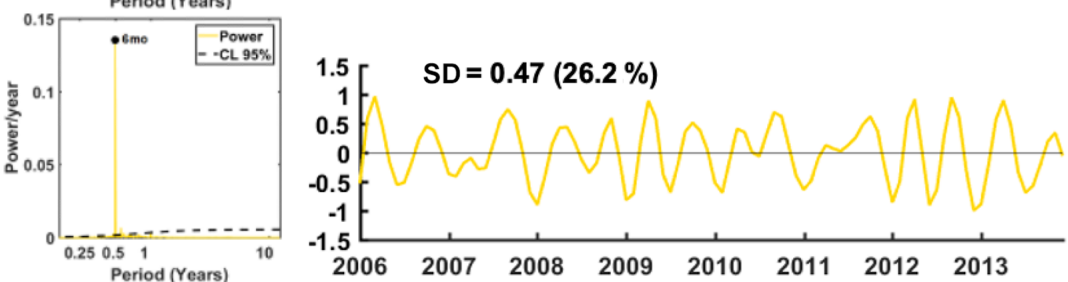

(f)
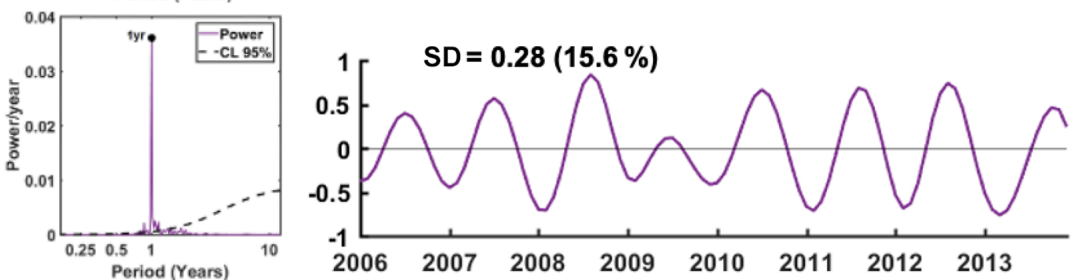

(g)
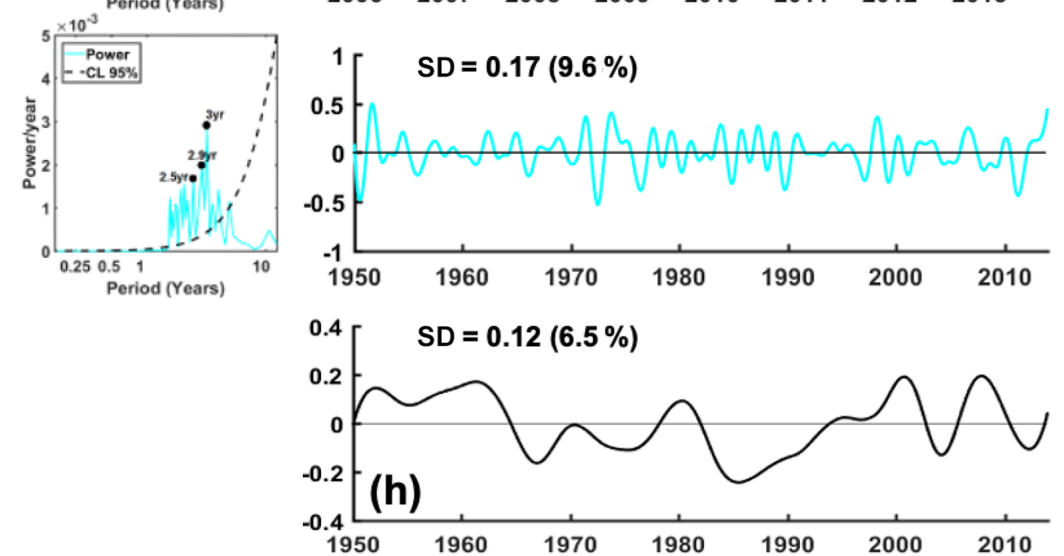

Figure 10. (a) Vertical mode structure and (b) its associated temporal variability of EOF1 (58\% of total variance) at the point AWJ. Panel (c) is the same as (b) but only shows the last 8-year period of the EOF1. The EEMD is then applied to the EOF temporal structure to decompose temporal variability: (d) intraseasonal, (e) semiannual, (f) annual, and (g) interannual variabilities with their corresponding red spectrum as a reference for $95 \%$ confidence limit (left column), whereas (h) represents the long-term variation and trend. Meanwhile, SD is standard deviation of each EEMD mode relative to the total variance of the EOF1.

El Niño (La Niña) events (Fieux et al., 1996; Meyers, 1996; Gordon and Susanto, 1999; Ffield et al., 2000; Susanto et al., 2001; Susanto and Gordon, 2005; Susanto et al., 2012; Liu et al., 2015; Susanto and Song, 2015; Zhang et al., 2016). ENSO seems to have a strongest influence on the zonal current variability at $\mathrm{C}_{\mathrm{EJ}}$ (Table 4), which is located close to the exits of the ITF. The ENSO signals penetrate into the SETIO mainly through the equatorial Pacific and coastal ocean In- donesian waveguides (Wijffels and Meyers, 2004; Zhang et al., 2016). Meanwhile, the present study shows that the correlation between the zonal current at $\mathrm{A}_{\mathrm{WJ}}$ and $\mathrm{ONI}$ is weak and below the significance level.

Furthermore, negative correlation is found between IOD and zonal currents at $\mathrm{A}_{\mathrm{WJ}}$ [DMI- $\left.U: r(9)=-0.09\right], \mathrm{B}_{\mathrm{SM}}$ [DMI- $U: r(1)=-0.28]$, and $\mathrm{C}_{\mathrm{EJ}}$ [DMI- $U: r(11)=-0.13$ ]. The correlation analysis indicates that IOD is most influ- 


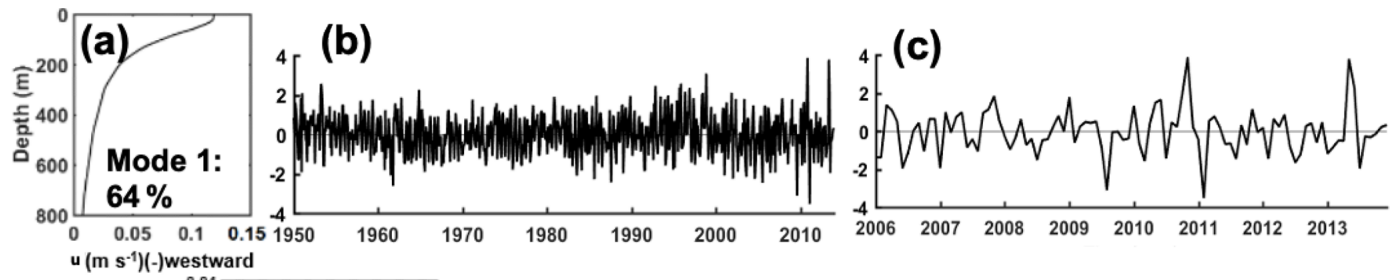

(d)
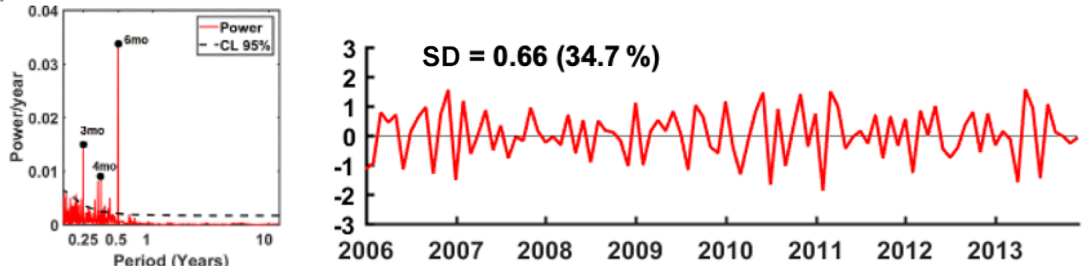

(e)
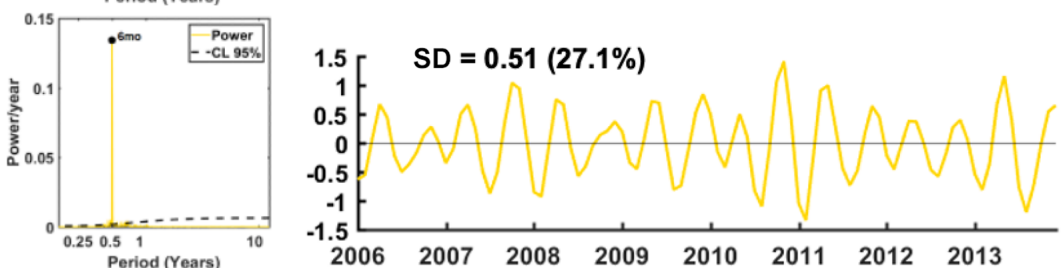

(f)

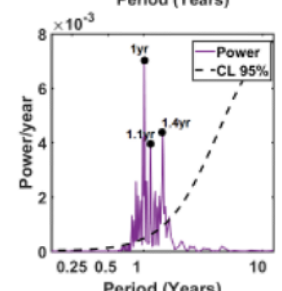

$\begin{array}{llllllll}2006 & 2007 & 2008 & 2009 & 2010 & 2011 & 2012 & 2013\end{array}$

(g)
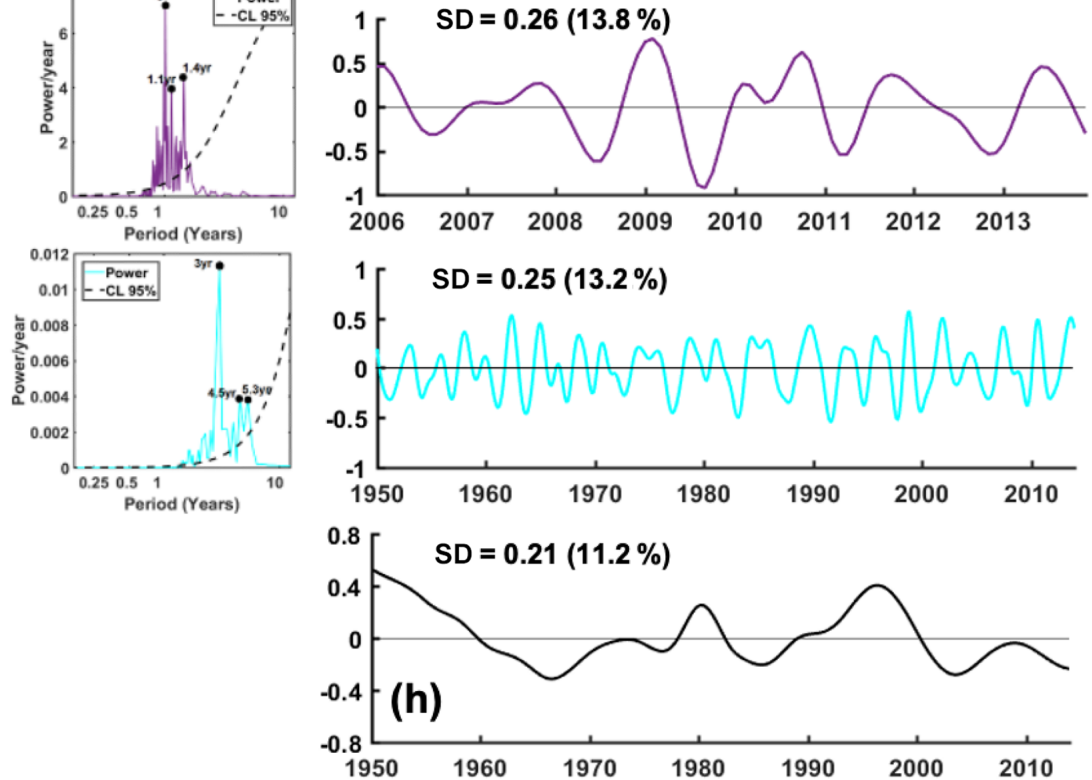

Figure 11. The same as Fig. 10 but for point $\mathrm{B}_{\mathrm{SM}}$, with the temporal variability of EOF1 accounting for $64 \%$ of total variance.

ential in forcing the interannual variation of the zonal currents at $\mathrm{B}_{\mathrm{SM}}$, with the IOD leading the zonal currents by 1 month. The influence of interannual phenomena at $\mathrm{B}_{\mathrm{SM}}$, such as IOD, is stronger and relatively instantaneous compared to that at points $\mathrm{C}_{\mathrm{EJ}}$ and $\mathrm{A}_{\mathrm{WJ}}$. This may be due to the location of $\mathrm{B}_{\mathrm{SM}}$, which is close to the center of the eastern pole of the IOD $\left(5^{\circ} \mathrm{S}, 100^{\circ} \mathrm{E}\right.$; Saji et al., 1999). In contrast to ONI, there are IOD signals at $A_{\mathrm{WJ}}$, although the IOD signals at this point are weak compared to $\mathrm{B}_{\mathrm{SM}}$ and $\mathrm{C}_{\mathrm{EJ}}$ (Table 4). This indicates that some of the IOD signals are coastally trapped.

Table 5 lists extreme and neutral years and their concurrent events through 1950-2013. To further investigate inter- annual variation of zonal current, we summarized presence of major climate modes (ENSO and/or IOD) and the corresponding current anomalies at the points of $\mathrm{B}_{\mathrm{SM}}$ and $\mathrm{C}_{\mathrm{EJ}}(\mathrm{Ta}-$ ble 6) based on the lagged correlation analyses in Table 4, the interannual variations of zonal current (Figs. $11 \mathrm{~g}$ and $12 \mathrm{~g}$ ), and the ONI and DMI (Fig. 13). In Table 4, the ONI- $U$ and DMI- $U$ correlations are independent of IOD and of ENSO, respectively. Meanwhile, the current anomalies, which are attributed to the presence of major climate modes (ENSO and/or IOD) shown in the Table 6, could be forced by ENSO, IOD, or their combined effect. In this study, the amounts of the contribution values of ENSO and IOD or their combined 


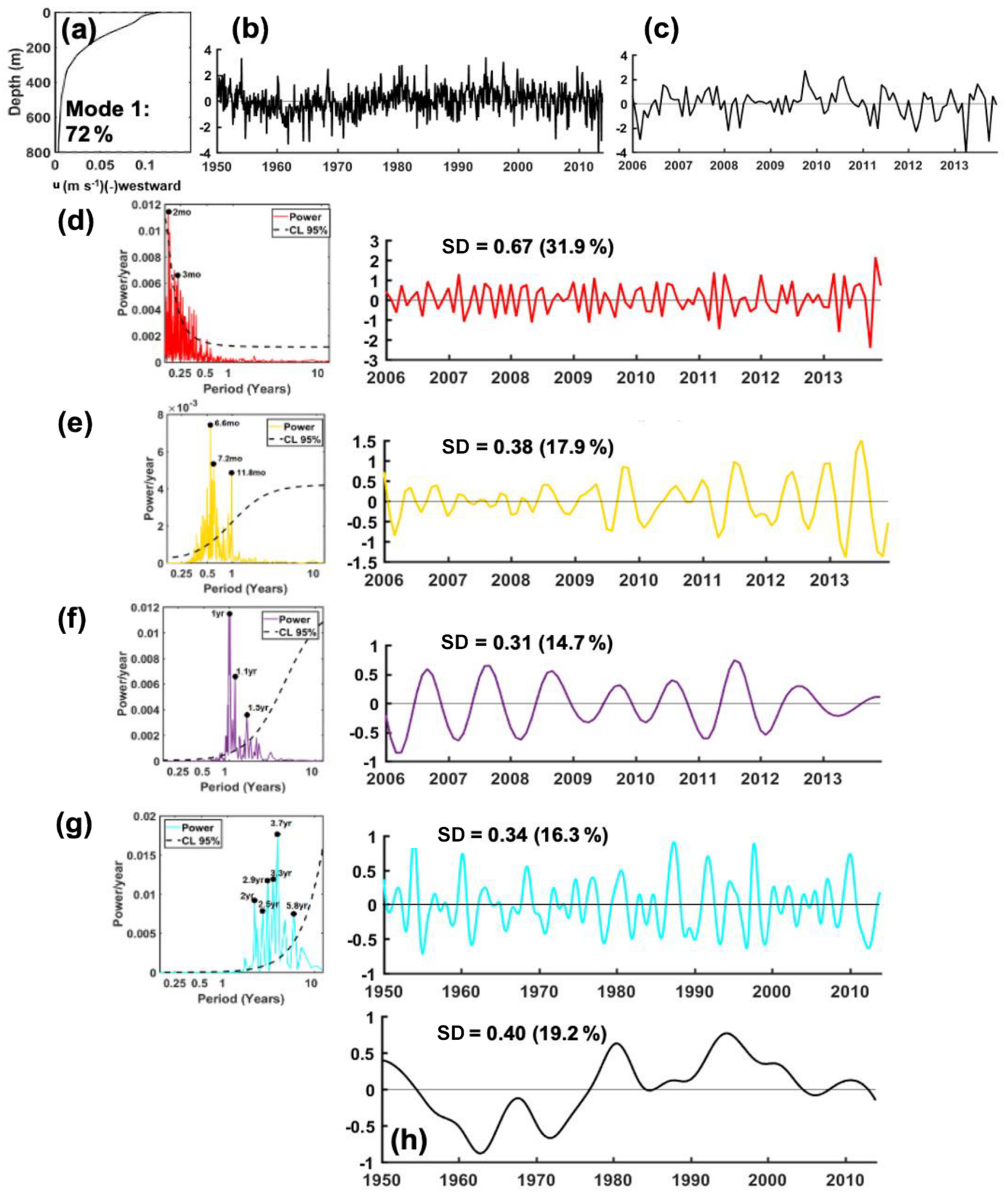

Figure 12. The same as Fig. 10 but for point $C_{E J}$, with the temporal variability of EOF1 accounting for $72 \%$ of total variance.

effect on the current anomalies shown in the Table 6 are still unknown. Further studies are thus required to more quantitatively determine the contribution values of each of climate mode on zonal current variations in the study area as well as their possible teleconnection.

In addition to the lagged correlation analysis (Table 4), partial correlation analysis was also conducted since the IOD tends to co-occur with ENSO. Table 7 shows the partial correlation coefficients between zonal currents at $30 \mathrm{~m}$ on an interannual timescale for both ONI and DMI. As for ONI, the currents revealed significant positive correlations at $\mathrm{C}_{\mathrm{EJ}}$ dur- ing all monsoon seasons. This positive correlation suggests that El Niño (La Niña) events caused an eastward (westward) anomaly of currents at this point. Meanwhile, the partial correlation between the currents and the DMI showed significant negative correlation at $\mathrm{B}_{\mathrm{SM}}$, in which it occurred only during the SE monsoon (JJA), as shown in Table 7. This negative correlation indicates that an eastward (westward) anomaly of the currents was induced by negative (positive) IOD. The results of the partial correlation analysis confirm and complement the previous findings in Table 4 that ENSO mainly contributed to the zonal current variability at $\mathrm{C}_{\mathrm{EJ}}$ in DJF, MAM, 

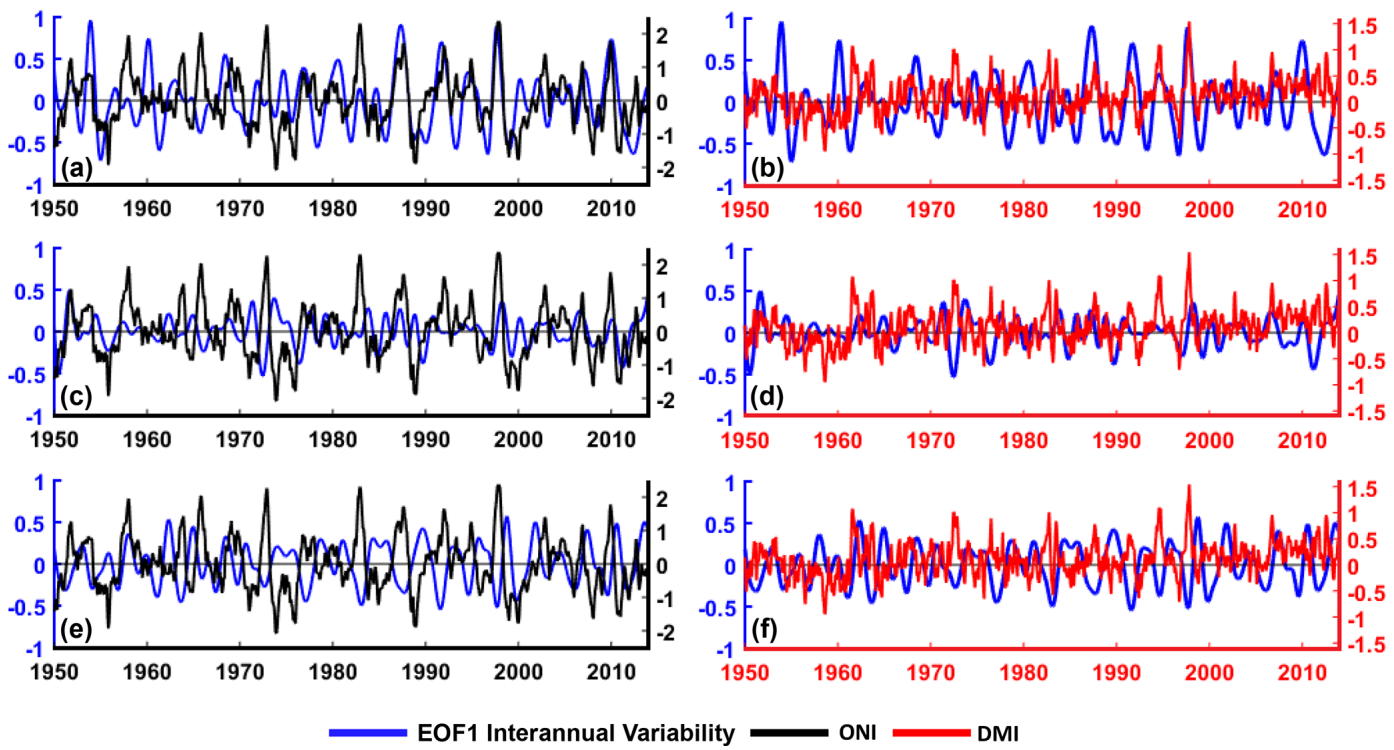

Figure 13. The interannual variability of the EOF first temporal mode (blue lines) overlaid with ONI (black lines) and DMI (red lines) at $\mathrm{C}_{\mathrm{EJ}}(\mathbf{a}, \mathbf{b}), \mathrm{A}_{W J}(\mathbf{c}, \mathbf{d})$, and $\mathrm{B}_{\mathrm{SM}}(\mathbf{e}, \mathbf{f})$.

Table 4. Lag correlation between the zonal currents at $30 \mathrm{~m}$ and each ONI and DMI.

\begin{tabular}{|c|c|c|c|c|}
\hline \multirow[t]{3}{*}{ Points } & \multicolumn{4}{|c|}{ Correlation coefficients $(r)^{\mathrm{a}}$ and time lag (TL) } \\
\hline & \multicolumn{2}{|c|}{ ONI- $U$} & \multicolumn{2}{|c|}{ DMI- $U$} \\
\hline & $r$ & TL (months) & $r$ & TL (months) \\
\hline$A_{W J}$ & $0.02^{\mathrm{b}}$ & 2 & -0.09 & 9 \\
\hline $\mathrm{B}_{\mathrm{SM}}$ & 0.24 & 18 & -0.28 & 1 \\
\hline $\mathrm{C}_{\mathrm{EJ}}$ & 0.27 & 4 & -0.13 & 11 \\
\hline \multicolumn{5}{|c|}{$\begin{array}{l}\text { a The } 95 \% \text { significance level is approximately } \pm 0.07 \text {. } U \text { indicates zonal } \\
\text { currents at } 30 \mathrm{~m} \text {. Positive correlation coefficients between the currents and } \\
\text { the ONI indicate the existence of an eastward (westward) anomaly of the } \\
\text { currents during El Niño (La Niña). Meanwhile, negative correlation } \\
\text { coefficients between the currents and the DMI indicate the existence of an } \\
\text { eastward (westward) anomaly of the currents during negative (positive) IOD. } \\
\text { A positive (negative) lag indicates that the variability in a former variable } \\
\text { (e.g., ONI or DMI) leads (lags) that in the latter variable (the zonal current). } \\
\text { b Correlation below the significance level. }\end{array}$} \\
\hline
\end{tabular}

JJA, and SON, whereas the IOD had a significant influence on the variability of the current at $\mathrm{B}_{\mathrm{SM}}$ and only in JJA. In this present study, however, determining the causes of the influence of IOD on the current variability at $\mathrm{B}_{\mathrm{SM}}$ only in JJA is still a work in progress. Further research is necessary to explain the dynamical links of this matter. Additionally, the last mode (Figs. 10h, 11h, and 12h) represents long-term variation and trends, which may be associated with long-term internal variability within the Indian Ocean or remote forcing from the Pacific Ocean, as will be discussed in detail in a future paper.

\subsubsection{Relationship of the zonal current variations at $A_{W J}, B_{S M}$, and $C_{E J}$ to both remote and local wind forcings}

To confirm possible influences of wind forcings on dominant variations of zonal current at $\mathrm{A}_{\mathrm{WJ}}, \mathrm{B}_{\mathrm{SM}}$, and $\mathrm{C}_{\mathrm{EJ}}$, we have calculated the correlation between them. In this study, it is found that the zonal currents at $\mathrm{A}_{\mathrm{WJ}}$ (close to the shore) have peak energy over a semiannual period $(0.140$ power per year; Table 3). The semiannual variations of the zonal current at $A_{W J}$ show the presence of an eastward anomaly of the zonal current during MAM and SON, which may be associated with Kelvin waves forced by winds over the equatorial Indian Ocean (Wyrtki, 1973; Quadfasel and Cresswell, 1992; Sprintall et al., 1999, 2000, 2010). Furthermore, we have calculated the correlation between zonal currents in the upper layer $(30 \mathrm{~m})$ at $A_{W J}$ and zonal winds for the semiannual signals extracted using the EEMD method (Fig. 15). The $30 \mathrm{~m}$ upper-layer flows at $A_{W J}$ show a strong positive correlation with the zonal winds over the equatorial Indian Ocean, with the winds leading the current by approximately 1 month. The positive correlation indicates that the flows are to the east when the winds blow from the west to the east and vice versa for the easterly wind. The 1-month lag between the flows at $A_{W J}$ and the zonal winds in the equatorial Indian Ocean is in agreement with the expected arrival time of Kelvin waves at this point, suggesting that it is of about $18-35 \mathrm{~d}$, with phase speeds ranging from 1.5 to $2.9 \mathrm{~m} \mathrm{~s}^{-1}$ (e.g., Sprintall et al., 2000; Syamsudin et al., 2004; Iskandar et al., 2005). Interestingly, there is also a weaker positive correlation between the $30 \mathrm{~m}$ upper-layer flows at $A_{W J}$ at a lag of about 1 month and zonal trade winds in the western equatorial Pacific 
(a)

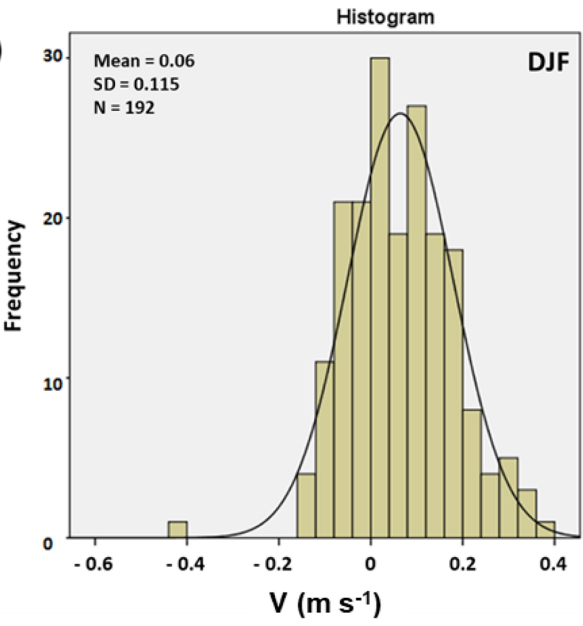

(c)

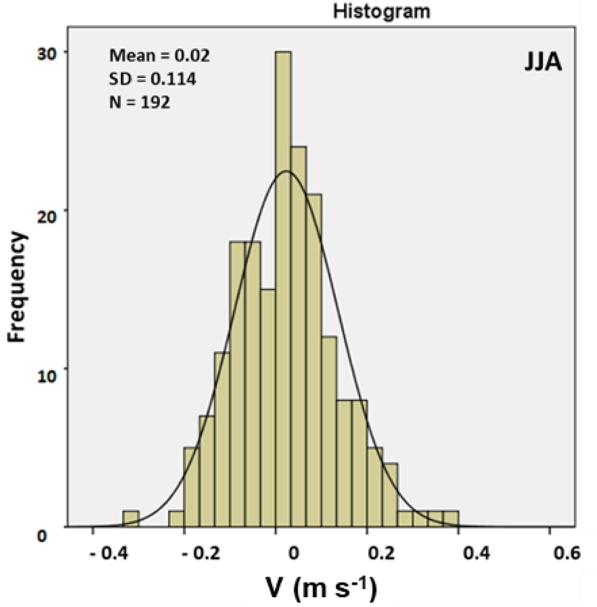

(b)

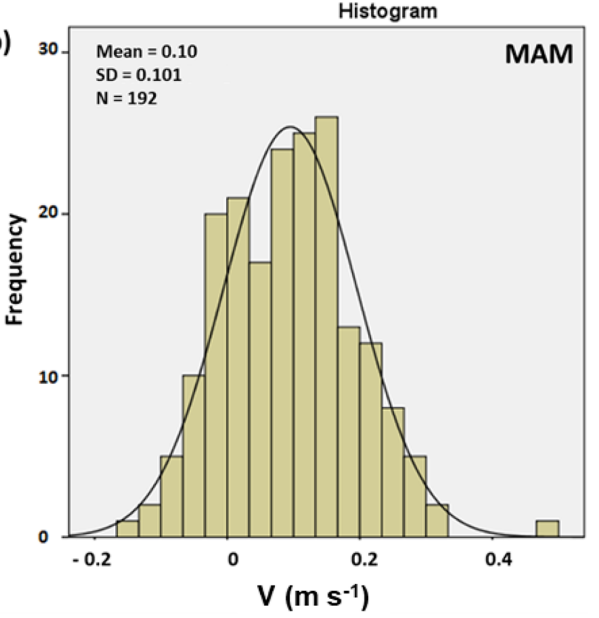

(d)

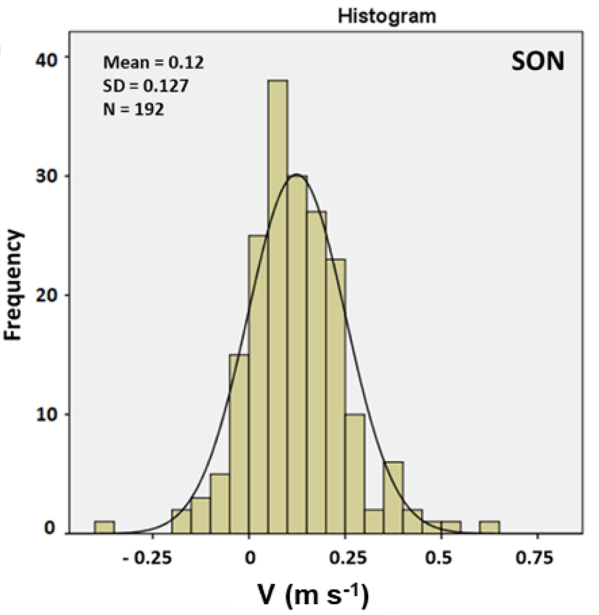

Figure 14. A probability distribution function of the EOF1 of zonal currents for the NW (a), SE (c), and transition (b, d) seasons at $\mathrm{B}_{\mathrm{SM}}$ at a depth of $\sim 40 \mathrm{~m}$.

Ocean (WEPO) at a semiannual timescale, indicating that a strengthening (weakening) of easterly trade winds over the WEPO is favorable for anomalous westward (eastward) currents at $A_{W J}$. The strengthening of easterly trade winds over the WEPO will increase the sea level in the northern waters of West Papua and New Guinea, enhancing the Pacific-toIndian pressure gradient across the Indonesian seas and forcing strengthened ITF transport. Since the currents at $A_{W J}$ are strongly correlated to the ITF (Table 1), it is suggested that this possible dynamic could result in anomalous westward currents at $A_{W J}$ and vice versa for the weakening winds over the WEPO.

Semiannual (0.135 power per year) signal of current variations is also dominant at $\mathrm{B}_{\mathrm{SM}}$, but it is weaker than that at $\mathrm{A}_{\mathrm{WJ}}$. In addition, there is pronounced interannual ( 0.012 power per year) variation of the zonal current at $\mathrm{B}_{\mathrm{SM}}$ (Table 3 and Fig. 11g), in which IOD is most influential in forcing interannual variation of currents at this point (at $30 \mathrm{~m}$ ), as shown in Table 4. Like at $A_{W J}$, we also look for the re-

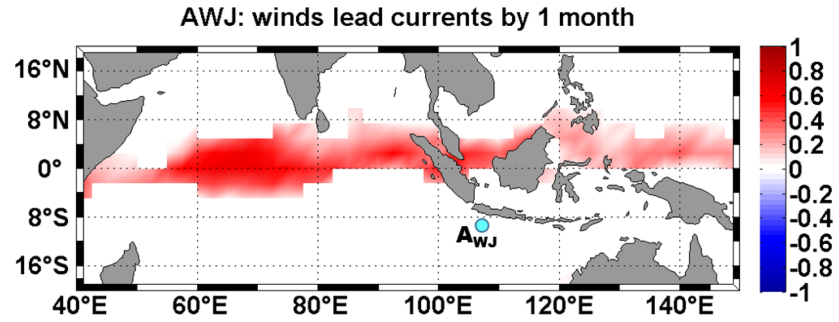

Figure 15. A correlation map between zonal wind and zonal currents $\left(\right.$ at $30 \mathrm{~m}$ ) at $A_{\mathrm{WJ}}$ for the semiannual signals extracted using the EEMD method. The $95 \%$ significance level is approximately \pm 0.07 .

lationships between the upper-layer flow $(30 \mathrm{~m})$ at $\mathrm{B}_{\mathrm{SM}}$ and the zonal winds but for the interannual signal obtained using the EEMD method (Fig. 16). At an interannual timescale, the $30 \mathrm{~m}$ upper-layer flows at $\mathrm{B}_{\mathrm{SM}}$ show a strong positive correlation with the zonal winds over the eastern tropical In- 
Table 5. ENSO, IOD, and neutral events during the 1950-2013 period.

\begin{tabular}{lccc|ccc|ccc}
\hline & \multicolumn{3}{c|}{ El Niño } & \multicolumn{3}{c|}{ NR-ENSO } & \multicolumn{3}{c}{ La Niña } \\
\hline P-IOD & 1951 & 1953 & 1963 & 1962 & 1967 & 1990 & 1970 & 1976 & 1985 \\
& 1965 & 1966 & 1969 & 2003 & 2013 & & 1999 & 2000 & 2006 \\
& 1972 & 1977 & 1982 & & & & 2007 & 2008 & 2010 \\
& 1983 & 1986 & 1987 & & & & 2011 & & \\
& 1991 & 1993 & 1994 & & & & & & \\
& 1997 & 2002 & 2004 & & & & & & \\
\hline NR-IOD & 2009 & 2012 & & & & & & & \\
& & & & 1952 & 1957 & 1961 & 1950 & 1971 & 1973 \\
& & & & 1979 & 2001 & 2005 & 1974 & 1988 & 1989 \\
N-IOD & 1968 & 1992 & & 1956 & 1958 & 1959 & 1954 & 1955 & 1964 \\
& & & & 1960 & 1978 & 1980 & 1975 & 1984 & 1998 \\
& & & 1981 & 1996 & & & & \\
\hline
\end{tabular}

NR-ENSO is neutral ENSO $\left(-0.5^{\circ} \mathrm{C}<\mathrm{ONI}<+0.5^{\circ} \mathrm{C}\right)$. El Niño $\left(\mathrm{ONI}>+0.5^{\circ} \mathrm{C}\right)$. La Niña $\left(\mathrm{ONI}<-0.5^{\circ} \mathrm{C}\right)$. P-IOD is positive IOD (DMI $\left.>+0.36^{\circ} \mathrm{C}\right)$. NR-IOD is neutral IOD $\left(-0.36^{\circ} \mathrm{C}<\mathrm{DMI}<+0.36^{\circ} \mathrm{C}\right)$. N-IOD is negative IOD $\left(\mathrm{DMI}<-0.36^{\circ} \mathrm{C}\right)$. The classification of ENSO events is determined by ONI

(http://www.ESRL.noaa.gov/, last access: 21 February 2021). Meanwhile, DMI is used for the classification of IOD events with criteria according to Yuan et al. (2008).

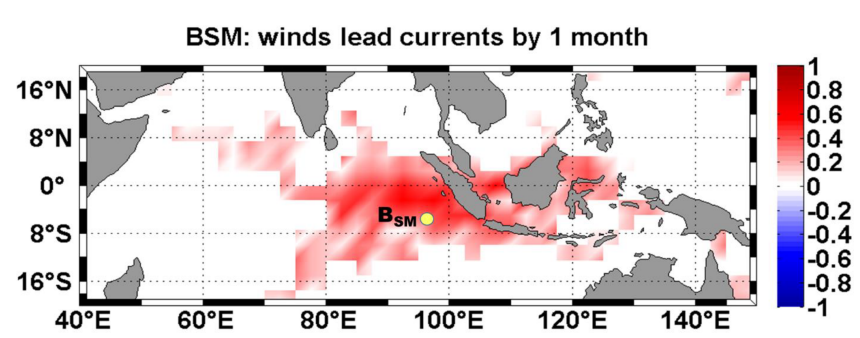

Figure 16. The same as Fig. 15 but at $\mathrm{B}_{\mathrm{SM}}$ and for interannual signal.

dian Ocean, in which the response of the flows to the zonal winds are relatively instantaneously at a lag of about 1 month (Fig. 16). The location of the zonal winds affecting interannual variations in the upper-layer flows at $\mathrm{B}_{\mathrm{SM}}$ is in accord with the eastern pole region of IOD $\left(10-0^{\circ} \mathrm{S}, 90-110^{\circ} \mathrm{E}\right.$; Saji et al., 1999).

Furthermore, as already explained, the zonal current variability at $\mathrm{C}_{\mathrm{EJ}}$ (close to the exits of the ITF) is dominated by an interannual ( 0.017 power per year) signal where the influence of ENSO is strongest at this point at depth of $30 \mathrm{~m}$ (Table 4). To enhance our understanding of the possible relationship of zonal currents at $\mathrm{C}_{\mathrm{EJ}}$ to wind forcings at an interannual timescale, we have also calculated the correlation between the upper-layer flow $(30 \mathrm{~m})$ at $\mathrm{C}_{\mathrm{EJ}}$ and the zonal winds, particularly in the Pacific Ocean. Like at $\mathrm{B}_{\mathrm{SM}}$, the interannual signals of both flows and winds are extracted using the EEMD method. At an interannual timescale, the flows at $\mathrm{C}_{\mathrm{EJ}}$ at $30 \mathrm{~m}$ show a significant positive correlation with the local winds and the remote winds over the equatorial Pacific Ocean, in which the response of the flows to the zonal winds are about 4 to 6 months. In addition, we also found that the

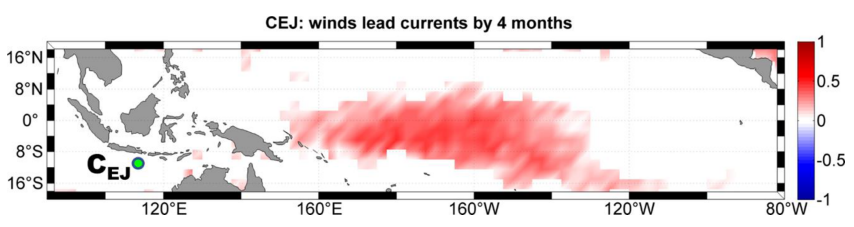

Figure 17. The same as Fig. 15 but at $\mathrm{C}_{\mathrm{EJ}}$ and for interannual signal.

4-month lag signal is stronger than the signals with the 5 to 6 months of lag. Figure 17 shows a correlation map between the Pacific winds and the currents at $\mathrm{C}_{\mathrm{EJ}}$ in the case of a 4month lag.

A previous study conducted by Wijffels and Meyers (2004) showed that the variability in the ITF region was associated with Kelvin and Rossby waves originating in the Indian and Pacific Oceans, respectively. They have revealed the pathways for equatorial Pacific wind energy traveling down the Papuan-Australian shelf break and radiating westward-propagating Rossby Waves into the Banda Sea and southeastern Indian Ocean (their Fig. 20). Hence, there is a contribution from the westward-propagating Rossby waves to the ITF variability inside the Indonesian seas or at the ITF exit regions (the Ombai and Lombok straits and the Timor Passage), which lead into the SETIO and the western coast of Sumatra and southern coast of Java. Our simulation (Fig. 2) clearly shows that ITF flowing from the exit passages of Indonesian seas (Lombok, Ombai, and Timor passages) feeds into the SETIO region. Moreover, Wijffels and Meyers (2004) have computed the remotely driven Pacific Rossby wave speeds as a function of latitude. The phase speeds have been compared with the theoretical Rossby wave speeds based on the atlas of Chelton et al. (1998). In this 
Table 6. Summary of major climate modes (ENSO and/or IOD) and the corresponding current anomalies through 1950-2013.

\begin{tabular}{|c|c|c|c|}
\hline \multirow[t]{2}{*}{ Points } & \multirow[t]{2}{*}{ Events } & \multicolumn{2}{|c|}{ Zonal current $(U)$} \\
\hline & & $\begin{array}{r}\text { Current speed } \\
\text { anomalies }\left(\mathrm{m} \mathrm{s}^{-1}\right)\end{array}$ & $\begin{array}{l}\text { Observation } \\
\text { time }\end{array}$ \\
\hline \multirow{9}{*}{$\mathrm{B}_{\mathrm{SM}}$} & NR-ENSO (Jan 2004) and NR-IOD (Jun 2005) & -0.21 & Jul 2005 \\
\hline & NR-ENSO (Dec 1980) and P-IOD (May 1982) & -0.19 & Jun 1982 \\
\hline & NR-ENSO (Aug 1962) and N-IOD (Jan 1964) & -0.28 & Feb 1964 \\
\hline & El Niño (Feb 1998) and P-IOD (Jul 1999) & -0.35 & Aug 1999 \\
\hline & El Niño (Oct 2009) and P-IOD (Apr 2011) & -0.18 & May 2011 \\
\hline & La Niña (Dec 1995) and P-IOD (Jul 1997) & -0.50 & Aug 1997 \\
\hline & La Niña (Aug 2007) and P-IOD (Feb 2009) & -0.16 & Mar 2009 \\
\hline & La Niña (Feb 1995) and N-IOD (Jul 1956) & -0.24 & Aug 1956 \\
\hline & La Niña (Oct 1955) and NR-IOD (Mar 1957) & -0.13 & Apr 1957 \\
\hline \multirow{12}{*}{$\mathrm{C}_{\mathrm{EJ}}$} & NR-ENSO (Oct 2001) and NR-IOD (Feb 2001) & -0.18 & Jan 2002 \\
\hline & NR-ENSO (May 1978) and P-IOD (Oct 1977) & -0.46 & Sep 1978 \\
\hline & NR-ENSO (Mar 1960) and N-IOD (Aug 1959) & 0.41 & Jul 1960 \\
\hline & El Niño (Aug 1953) and P-IOD (Jan 1953) & 0.96 & Dec 1953 \\
\hline & El Niño (Nov 1991) and P-IOD (Apr 1991) & 0.45 & Mar 1992 \\
\hline & El Niño (Nov 2009) and P-IOD (Apr 2009) & 0.69 & Jan 2010 \\
\hline & El Niño (Jul 1997) and N-IOD (Dec 1996) & 0.78 & Nov 1997 \\
\hline & La Niña (May 1988) and P-IOD (Oct 1987) & -0.46 & Sep 1988 \\
\hline & La Niña (Sep 1998) and P-IOD (Feb 1998) & -0.59 & Jan 1999 \\
\hline & La Niña (Nov 2011) and P-IOD (Apr 2011) & -0.61 & Mar 2012 \\
\hline & La Niña (Aug 1954) and NR-IOD (Jan 1954) & -0.70 & Dec 1954 \\
\hline & La Niña (Sep 1988) and NR-IOD (Feb 1988) & -0.43 & Jan 1989 \\
\hline
\end{tabular}

NR-ENSO is neutral ENSO, P-IOD is positive IOD, NR-IOD is neutral IOD, N-IOD is negative IOD. The classification criteria for ENSO and IOD events can be seen in Table 5 .

Table 7. Partial correlation coefficients between zonal currents at $30 \mathrm{~m}$ on an interannual timescale for both ONI and DMI. Only values above the $95 \%$ significance level are shown.

\begin{tabular}{lrrrr|rrrr}
\hline \multirow{2}{*}{ Points } & \multicolumn{3}{c|}{ ONI- $U$ (no DMI) } & \multicolumn{4}{c}{ DMI- $U$ (no ONI) } \\
\cline { 2 - 8 } & DJF & MAM & JJA & SON & DJF & MAM & JJA & SON \\
\hline A & - & - & - & - & - & - & - & - \\
B $_{\text {SM }}$ & - & - & - & - & - & - & -0.76 & - \\
$C_{\text {EJ }}$ & 0.46 & 0.28 & 0.47 & 0.43 & - & - & - & - \\
\hline $\begin{array}{l}\text { The 95 \% } \\
\text { significance }\end{array}$ & \pm 0.19 & \pm 0.25 & \pm 0.26 & \pm 0.23 & \pm 0.63 & \pm 0.49 & \pm 0.35 & \pm 0.41 \\
level & & & & & & & & \\
\hline
\end{tabular}

study, we have estimated the travel time of the westwardpropagating Rossby waves excited by the wind anomalies in the central and western Pacific to the SETIO, especially at point $\mathrm{C}_{\mathrm{EJ}}$, based on the pathways for the Pacific signals introduced by Wijffels and Meyers (2004). In general, it was found that the equatorial Pacific signals around $130^{\circ} \mathrm{W}$ took approximately 3.01 months to arrive at $\mathrm{C}_{\mathrm{EJ}}$ based on the mean phase speed of about $0.2 \mathrm{~cm} \mathrm{~s}^{-1}$ taken from Wijffels and Meyers (2004). This travel time estimation was within the range of the 4-month lags between the flows at $\mathrm{C}_{\mathrm{EJ}}$ and the Pacific winds derived from the lagged correlation analysis in Fig. 17.

\section{Conclusions}

Basic features of zonal currents and their temporal variability in the SETIO region adjacent to the southern coasts of Sumatra and Java have been studied using global HYCOM output over the course of 1950-2013. There are peculiar features of zonal currents in the coastal (the SJC) region, offshore (the ITF-SEC) region, and the transition zone between coastal and offshore regions of the SETIO. In general, surface zonal currents in Transect A (the SJC region), especially along the southern coasts of Sumatra and Java $\left(98-114^{\circ} \mathrm{E}\right)$, show seasonal characteristics, i.e., they are eastward (west- 
ward) during DJF (JJA). Moreover, the eastward-flowing currents are enhanced during MAM and SON, and this is associated with the propagation of coastal Kelvin waves. On the other hand, westward currents are dominant along Transect C (the ITF-SEC region). Meanwhile, although westward currents are quite dominant along Transect $\mathrm{B}$ (the transition zone between the SJC region and ITF-SEC region), eastward currents are also present, especially at longitudes $95-107^{\circ} \mathrm{E}$.

In the period of 1950 through 2013, the mean (climatological) current velocity of SJC on Transect A is dominantly eastward. We found that both remote and local wind forcings and seasonal conditions are necessary to explain the current variability in the study area. During JJA, the strength of climatological eastward SJC reduced, and the SJC in the upper $100 \mathrm{~m}$ along the southern coast of Java, at a certain period of time, flowed westward in response to the prevailing southeasterly local winds during those months. At the depth $100 \mathrm{~m}$, there is a maximum westward current at $A_{W J}$ during DJF with a velocity of about $0.1 \mathrm{~m} \mathrm{~s}^{-1}$, wherein the current at $A_{W J}$ shows high correlation with the subsurface $(200 \mathrm{~m})$ maximum ITF in the southern Ombai Strait (remote forcing), whereas its correlation with the NW local wind is weak. Otherwise, it is found that the NW zonal wind is more influential in forcing variation in zonal current at $\mathrm{A}_{\mathrm{EJ}}$ than the ITF. Therefore, it is suggested that the westward current simulated at $A_{W J}$ at $100 \mathrm{~m}$ during DJF is ITF related, whereas that at $A_{E J}$ at $100 \mathrm{~m}$ is relatively NW zonal wind related.

Moreover, it is found that the average (climatological) current at $\mathrm{B}_{\mathrm{SM}}$ is eastward, while at points $\mathrm{B}_{\mathrm{WJ}}$ and $\mathrm{B}_{\mathrm{EJ}}$ it is westward, suggesting that the mean eastward current at $\mathrm{B}_{\mathrm{SM}}$ is influenced by tropical current systems in the Indian Ocean, such as the ECC, SWMC, and Wyrtki Jet, whereas the mean westward currents at the points $\mathrm{B}_{\mathrm{WJ}}$ and $\mathrm{B}_{\mathrm{EJ}}$ are more dominated by the ITF. In contrast, current characteristics on Transect $\mathrm{C}$ (offshore region) generally show similarities at all points $\left(\mathrm{C}_{\mathrm{SM}}, \mathrm{C}_{\mathrm{WJ}}\right.$, and $\left.\mathrm{C}_{\mathrm{EJ}}\right)$, where the current along this transect flows westward throughout the year, confirming that Transect C is the SEC or ITF region. Seasonal variation in the westward current on the Transect $C$ agrees well with that of ITF in Lombok Strait, Timor Passage, and through the three exit passages (the total ITF through the Lombok and Ombai straits and Timor Passage), in which during JJA the flow is stronger than during DJF.

The EOF1 mode of zonal current across the three meridional sections (EJ, WJ, and SM) clearly shows unique features of zonal currents between nearshore and offshore regions in the sections. In Sections EJ and WJ, the vertical structure of EOF1 is characterized by one-layer flow. In the nearshore area of Section EJ, the vertical structure of EOF1 displays a gradual decrease in speed from the surface to $800 \mathrm{~m}$ depth, whereas in the transition and the offshore areas the flow velocities decline more rapidly with depth, reducing to nearly zero at depths of about 500 and $300 \mathrm{~m}$, respectively. Meanwhile, in Section WJ, the one-layer flow of the vertical structure of EOF1 shows a unidirectional vertical structure that gradually decreases from the surface to a depth of $\sim 450 \mathrm{~m}$ in all areas. On the contrary, in the nearshore and transition regions of Section SM, it is marked by twolayer flow, in which the velocity reversal between the two types of flow takes place at depths of approximately 100 and $200 \mathrm{~m}$, respectively. Meanwhile, in the offshore area of Section SM, the vertical structure of EOF1 exhibits a unidirectional flow from the surface to a depth of about $500 \mathrm{~m}$.

In this study, the predominant variations in content of the zonal current anomalies in the region is quantitatively identified, varying from intraseasonal to interannual timescales. The analysis indicates that the zonal currents at $\mathrm{A}_{\mathrm{WJ}}$ (close to the shore) have peak energies that are successively dominated by semiannual, intraseasonal, and annual periods, and it can be seen that the interannual period is weaker than the others at this point. Moreover, although semiannual and intraseasonal variations are dominant at $\mathrm{B}_{\mathrm{SM}}$ (close to the center of the eastern pole of the IOD), there is pronounced interannual variation in the zonal current at this point. In contrast, the zonal current variability at $\mathrm{C}_{\mathrm{EJ}}$ (close to the major exit passages of the ITF) is dominated by interannual signal. Nevertheless, in addition to the interannual signal, the power spectrum analysis shows that intraseasonal variability of the zonal current (SEC) at $\mathrm{C}_{\mathrm{EJ}}$ is also prominent. The lagged correlation analysis shows that ENSO seems to have the strongest influence on the zonal current variability at $\mathrm{C}_{\mathrm{EJ}}$, with the zonal current lagging the ENSO by 4 months. Meanwhile, the IOD is most dominant in controlling interannual fluctuation of the zonal current at $\mathrm{B}_{\mathrm{SM}}$, with the IOD leading the zonal currents by 1 month. Furthermore, based on the partial correlation analysis, it has been revealed that ENSO contributes to the zonal current variation at $\mathrm{C}_{\mathrm{EJ}}$ in all monsoon seasons (DJF, MAM, JJA, and SON), while the IOD plays a significant role in controlling the variation of current at $\mathrm{B}_{\mathrm{SM}}$ only in JJA. In this study, the dynamical links that cause the influence of IOD on the current variability at $\mathrm{B}_{\mathrm{SM}}$ only in JJA are still not known. Therefore, further study is essential to elucidate the physical mechanisms responsible for this topic. Here, the proportion calculation of contribution of each EEMD mode to the EOF1 showed that the order of each mode's contribution from largest to smallest at $A_{W J}$ and $B_{S M}$ is as follows: intraseasonal, semiannual, annual, interannual, and long-term signals. Interestingly, the contribution of longterm signal at $\mathrm{C}_{\mathrm{EJ}}$ is larger than the interannual and annual signals. However, the detailed analysis of long-term signal is not within the scope of this research and can be considered in a future study. Moreover, future work, including detailing the forcing mechanisms, investigating decadal variability and determining the cause of the long-term signals, will be necessary in order to gain a better understanding of these interesting topics.

Data availability. The HYCOM zonal currents used in this study are freely available at the Research Group of Oceanography-ITB 
website https://www.oceanography.fitb.itb.ac.id/member/nsn/ (last access: 5 June 2020), simulated and already published by Hanifah and Ningsih (2016).

Author contributions. NSN formulated research goals and aims, developed the methodology, conducted the investigation process, designed the model, and prepared the published work. SLS maintained the research data, prepared the data presentation, and drafted the initial manuscript. RDS supervised the research project and EEMD methodology. FH designed the model simulation and validated the model results.

Competing interests. The authors declare that they have no conflict of interest.

Disclaimer. Publisher's note: Copernicus Publications remains neutral with regard to jurisdictional claims in published maps and institutional affiliations.

Acknowledgements. The authors would like to gratefully acknowledge data support from NOAA for providing the moored RAMA current, wind fields, and ONI; PODAAC for providing the OSCAR dataset; and JAMSTEC for producing the DMI. The authors are also grateful to INSTANT, a multi-national programme with Indonesia, Australia, France, Netherlands, and the USA, for distributing the INSTANT current. Moreover, we would like to acknowledge the support given by the Indonesian Ministry of Education, Culture, Research and Technology (Kemendikbudristek) for making the writing of this paper possible. Finally, we really appreciate the valuable suggestions, comments, and corrections from the anonymous reviewers.

Financial support. This research has been supported by the Indonesian Ministry of Education, Culture, Research and Technology under the Basic Research Grant 2019-2021 (grant no. 2/E1/KP.PTNBH/2019, 2/E1/KP.PTNBH/2020, and 2/E1/KP.PTNBH/2021). Raden Dwi Susanto is supported by World Class Professor (WCP) Program 2018 managed by the Indonesian Ministry of Education and Culture (Kemendikbud) (grant no. 123.21/D2.3/KP/2018), the National Aeronautics and Space Administration (NASA) (grant no. 80NSSC18K0777 and NNX17AE79A) through the University of Maryland, and a Jet Propulsion Laboratory-NASA subcontract (grant no. 1554354).

Review statement. This paper was edited by Viviane Menezes and reviewed by two anonymous referees.

\section{References}

Bray, N. A., Wijffels, S. E., Chong, J. C., Fieux, M., Hautala, S., Meyers, G., and Morawitz, W. M. L.: Characteristics of the Indo-
Pacific throughflow in the Eastern Indian Ocean, Geophys. Res Lett., 24, 2569-2572, 1997.

Chelton, D. B., de Szoeke, R. A., Schlax, M.G., El Naggar, K. and Siwertz, N.: Geographical variability of the first-baroclinic Rossby radius of deformation, J. Phys. Oceanogr., 28, 433-460, 1998.

Clark, C. O., Webster, P. J., and Cole, J. E.: Interdecadal variability of the relationship between the Indian Ocean zonal mode and East African coastal rainfall anomalies, J. Clim., 16, 548-554, 2003.

Codiga, D. L., Renourad, D. P., and Fincham, A.: Experiments on waves trapped over the continental slope and shelf in a continuously stratified rotating ocean, J. Mar. Res., 57, 585-612, https://doi.org/10.1357/002224099321549602, 1999.

Ding, X., Bassinot, F., Guichard, F., and Fang, N. Q.: Indonesian throughflow and monsoon activity records in the Timor Sea since the last glacial maximum, Mar. Micropaleontol., 101, 115-126, https://doi.org/10.1016/j.marmicro.2013.02.003, 2013.

Drushka, K., Sprintall, J., Gille, S., and Brodjonegoro, I.: Vertical structure of Kelvin waves in the Indonesian throughflow exit passages, J. Phys. Oceanogr., 40, 1965-1987, https://doi.org/10.1175/2010JPO4380.1, 2010.

Duan, Y., Liu, L., Han, G., Liu, H., Yu, W., Yang, G., Wang, H., Wang, H., Liu, Y., Zahid, and Waheed, H.: Anomalous behaviors of Wyrtki Jets in the equatorial Indian Ocean during 2013, Sci Rep., 6, 1-7, https://doi.org/10.1038/srep29688, 2016.

Emery, W. J. and Thomson, R. E.: Data Analysis Methods in Physical Oceanography, Elsevier, New York, 2001.

Fang, G., Wang, Y., Wei, Z., Fang, Y., Qiao, F., and Hu, X.: Interocean circulation and heat and freshwater budgets of the South China Sea based on numerical model, Dynam. Atmos. Ocean, 47, 55-72, https://doi.org/10.1016/j.dynatmoce.2008.09.003, 2009.

Feng, M. and Wijffels, S.: Intraseasonal variability in the South Equatorial Current of the East Indian Ocean, J. Phys. Oceanogr., 32, 265-277, 2002.

Feng, M., Zhang, N., Liu, Q., and Wijffels, S.: The Indonesian throughflow, its variability and centennial change, Geosci. Lett., 5, 1-10, https://doi.org/10.1186/s40562-018-0102-2, 2018.

Ffield, A., Vranes, K., Gordon, A. L., Susanto, R. D., and Garzoli, S. L.: Temperature variability within Makassar Strait, Geophys. Res. Lett., 27, 237-240, 2000.

Fieux, M., Andrie, C., Delecluse, P., Ilahude, A. G., Kartavtseff, A., Mantisi, F., Molcard, R., and Swallow, J. C.: Measurements within the Pacific-Indian Ocean throughflow region, Deep-Sea Res., 41, 1091-1130, https://doi.org/10.1016/09670637(94)90020-5, 1994.

Fieux, M., Molcard, R., and Ilahude, A. G.: Geostrophic transport of the Pacific-Indian Oceans throughflow, J. Geophys. Res., 101, 12421-12432, https://doi.org/10.1029/95JC03566, 1996.

Gordon, A. L.: Interocean exchange of thermocline water, J. Geophys. Res., 91, 5037-5046, https://doi.org/10.1029/JC091iC04p05037, 1986.

Gordon, A. L. and Susanto, R. D.: Makassar Strait transport: initial estimate based on Arlindo result, Mar. Technol. Soc. J., 32, 34 45, 1999.

Gordon, A. L., Susanto, R. D., Ffield, A., Huber, B. A., Pranowo, W., and Wirasantosa, S.: Makassar Strait throughflow, 2004 to 2006, Geophys. Res. Lett., 35, L24605, https://doi.org/10.1029/2008GL036372, 2008. 
Hallock, Z. R., Teague, W. J., and Jarosz, E.: Subinertial slope trapped waves in the northeastern Gulf of Mexico, J. Phys. Oceanogr., 39, 1474-1485, https://doi.org/10.1175/2009JPO3925.1, 2009.

Han, W., McCreary Jr., J. P., Anderson, D. L. T., and Mariano A. J.: Dynamics of the eastern surface jets in the equatorial Indian Ocean, J. Phys. Oceanogr., 29, 2191-2209, 1999.

Hannachi, A.: A Primer for EOF Analysis of Climate Data, Department of Meteorology, University of Reading, UK, 2004.

Hanifah, F. and Ningsih, N. S.: The characteristic of eddies in the Banda Sea, Adv. Appl. Fluid Mech., 19, 889-902, https://doi.org/10.17654/FM019040889, 2016.

$\mathrm{Hu}, \mathrm{S}$. and Sprintall, J.: Interannual variability of the Indonesian Throughflow: The salinity effect, J. Geophys. Res.-Ocean., 121, 2596-2615, https://doi.org/10.1002/2015JC011495, 2016.

$\mathrm{Hu}, \mathrm{S}$. and Sprintall, J.: Observed strengthening of interbasin exchange via the Indonesian seas due to rainfall intensification, Geophys. Res. Lett., 44, 1448-1456, https://doi.org/10.1002/2016GL072494, 2017.

Huang, N. E., Shen, Z., Long, S. R., Wu, M. C., Shih, H. H., Zheng, Q., Yen, N-C., Tung, C. C., and Liu, H. H.: The empirical mode decomposition and the Hilbert spectrum for nonlinear and non-stationary time series analysis, Roy. Soc., 454, 903-905, https://doi.org/10.1098/rspa.1998.0193, 1998.

Iskandar, I., Mardiansyah, W., Masumoto, Y., and Yamagata, T.: Intraseasonal Kelvin waves along the southern coast of Sumatra and Java, J. Geophys. Res., 110, C04013, https://doi.org/10.1029/2004JC002508, 2005.

Iskandar, I., Tozuka, T., Sasaki, H., Masumoto, Y., and Yamagata, T.: Intraseasonal variations of surface and subsurface currents off Java as simulated in a high-resolution ocean general circulation model, J. Geophys. Res., 111, C12015, https://doi.org/10.1029/2006JC003486, 2006.

Iskandar, I., Masumoto, Y., and Mizuno, K.: Subsurface equatorial zonal current in the eastern Indian Ocean, J. Geophys. Res., 114, C06005, https://doi.org/10.1029/2008JC005188, 2009.

Iskandar, I., Masumoto, Y., Mizuno, K., Sasaki, H., Affandi, A. K., Setiabudidaya, D., and Syamsuddin, F.: Coherent intraseasonal oceanic variations in the eastern equatorial Indian Ocean and in the Lombok and Ombai Straits from observations and a high-resolution OGCM, J. Geophys. Res.-Ocean., 119, 615-630, https://doi.org/10.1002/2013JC009592, 2014.

Jyoti, J., Swapna, P., Krishnan, R., and Naidu, C. V.: Pacific modulation of accelerated south Indian Ocean sea level rise during the early 21st Century, Clim. Dynam., 53, 4413-4432, https://doi.org/10.1007/s00382-019-04795-0, 2019.

Kantha, L. H. and Clayson, C. A.: Numerical Models of Oceans and Oceanic Processes, International Geophysics Series, 66, Academic Press, London, 2000.

Knox, R. A.: On a long series of measurements of Indian Ocean equatorial currents near Addu Atoll, Deep-Sea Res., 23, 211221, https://doi.org/10.1016/0011-7471(76)91325-5, 1976.

Krishnamurthy, L. and Krishnamurthy, V.: Decadal and interannual variability of the Indian Ocean SST, Clim. Dynam., 46, 57-70, https://doi.org/10.1007/s00382-015-2568-3, 2016.

Liu, Q, Feng, M., Wang, D., and Wijffels, S.: Interannual variability of the Indonesian Throughflow transport: a revisit based on 30year expendable bathythermograph data, J. Geophys. Res., 120, 8270-8282, https://doi.org/10.1002/2015JC011351, 2015.
Mann, M. E. and Lees, J. M.: Robust estimation of background noise and signal detection in climatic time series, Clim. Change, 33, 409-445, 1996.

McPhaden, M. J.: Variability in the central equatorial Indian Ocean, Part I: Ocean dynamics, J. Mar. Res., 40, 157-176, 1982.

McPhaden, M. J., Wang, Y., and Ravichandran, M.: Volume transports of the Wyrtki Jets and their relationship to the Indian Ocean dipole, J. Geophys. Res., 120, 5302-5317, https://doi.org/10.1002/2015JC010901, 2015.

Meng, X., Wu, D., Hu, R., and Lan, J.: The interdecadal variation of Indonesian throughflow and its mechanism, Chinese Sci Bull., 49, 2058-2067, https://doi.org/10.1360/03wd0540, 2004.

Metzger, E. J., Hurlburt, H. E, Xu, X., Shriver, J. F., Gordon, A. L., Sprintall, J., Susanto, R. D., and van Aken, H. M.: Simulated and observed circulation in the Indonesian Seas $1 / 12^{\circ}$ global HYCOM and the INSTANT Observation, Dynam. Atmos. Ocean., 50, 275-300, https://doi.org/10.1016/j.dynatmoce.2010.04.002, 2010.

Meyers, G.: Variation of Indonesian throughflow and the El Niño Southern Oscillation, J. Geophys. Res., 101, 12,255-12,263. https://doi.org/10.1029/95JC03729, 1996.

Murray, S. P., and Arief, D.: Throughflow into the Indian Ocean through the Lombok Strait, January 1985-January 1986, Nat., 333, 444-447, 1988.

Potemra, J. T.: Seasonal variations of upper ocean transport from the Pacific to the Indian Ocean via Indonesian straits, J. Phys. Oceanogr., 29, 2930-2944, 1999.

Pujiana, K., Gordon, A. L., and Sprintall, J.: Intraseasonal Kelvin wave in Makassar Strait, J. Geophys. Res., 40, 2023-2034, https://doi.org/10.1002/jgrc.20069, 2013.

Pujiana, K., McPhaden, M. J., Gordon, A. L., and Napitu, A.: Unprecedented response of Indonesian Throughflow to anomalous Indo-Pacific climatic forcing in 2016, J. Geophys. Res.-Ocean., 124, 3737-3754, https://doi.org/10.1029/2018JC014574, 2019.

Qiu, Y., Li, L., and Yu, W.: Behavior of the Wyrtki Jet observed with surface drifting buoys and satellite altimeter, Geophys. Res. Lett., 36, 120-131, https://doi.org/10.1029/2009GL039120, 2009.

$\mathrm{Qu}, \mathrm{T}$. and Meyers, G.: Seasonal characteristics of circulation in the southeastern tropical Indian Ocean, J. Phys. Oceanogr., 35, 255267, https://doi.org/10.1175/JPO-2682.1, 2005.

Quadfasel, D. and Cresswell, G. R.: A note on seasonal variability of the South Java Current, J. Geophys. Res., 97, 3685-3688, https://doi.org/10.1029/91JC03056, 1992.

Saji N. H., Goswani, B. N., Vinayachandran, P. N., and Yamagata, T.: A dipole mode in the tropical Indian Ocean, Nature, 401, 360363, https://doi.org/10.1038/43854, 1999.

Saji, N. H. and Yamagata, T.: Possible impacts of Indian Ocean dipole mode events on global climate, Clim. Res., 25, 151-169, https://doi.org/10.3354/cr025151, 2003.

Semtner, A. J. and Chervin, R. M.: Ocean general circulation from a global eddy-resolving model, J. Geophys. Res., 97, 5493-5550, https://doi.org/10.1029/92JC00095, 1992.

Shen, B.-W., Cheung, S., Wu, Y.-L., Li, J.-L. F., and Kao, D.: Parallel implementation of the ensemble empirical mode decomposition and its application for earth science data analysis, Comput. Sci. Eng., 19, 49-57, https://doi.org/10.1109/MCSE.2017.3421555, 2017.

Shinoda, T., Han, W., Metzger, E. J., and Hurlburt, H.: Seasonal variation of the Indonesian through flow in Makassar Strait, J. 
Phys. Oceanogr., 42, 1099-1123, https://doi.org/10.1175/JPOD-11-0120.1, 2012.

Song, Q., Gordon, A. L., and Visbeck, M.: Spreading of the Indonesian throughflow in the Indian Ocean, J. Phys. Oceanogr., 34, 772-792, 2004.

Sprintall, J. and Révelard, J.: The Indonesian throughflow response to Indo-Pacific climate variability, J. Geophys. Res.-Ocean., 119, 1161-1175, https://doi.org/10.1002/2013JC009533, 2014.

Sprintall, J., Chong, J., Syamsudin, F., Morawitz, W., Hautala, S., Bray, N., and Wijffels, S.: Dynamics of the South Java Current in the Indo-Australian basin, Geophys. Res. Lett., 26, 2493-2496, https://doi.org/10.1029/1999GL002320, 1999.

Sprintall, J., Gordon, A. L., Murtugudde, R., and Susanto, R. D.: A semi-annual Indian Ocean forced Kelvin waves observed in the Indonesian Seas, May 1997, J. Geophys. Res., 105, $17217-$ 17230, https://doi.org/10.1029/2000JC900065, 2000.

Sprintall, J., Wijffels, S. E., Molcard, R., and Jaya, I.: Direct estimates of the Indonesian throughflow entering the Indian Ocean: 2004-2006, J. Geophys. Res., 114, C07001, https://doi.org/10.1029/2008JC005257, 2009.

Sprintall, J., Wijffels, S. E., Molcard, R., and Jaya, I.: Direct evidence of the south Java current in Ombai Strait, Dynam. Atmos. Ocean., 50, 140-156, https://doi.org/10.1016/j.dynatmoce.2010.02.006, 2010.

Susanto, R. D. and Gordon, A. L.: Velocity and transport of the Makassar Strait throughflow, J. Geophys. Res., 110, C01005, https://doi.org/10.1029/2004JC002425, 2005.

Susanto, R. D. and Song, Y. T.: Indonesian throughflow proxy from satellite altimeters and gravimeters, J. Geophys. Res.-Ocean., 120, 2844-2855, https://doi.org/10.1002/2014JC010382, 2015.

Susanto, R. D., Gordon, A. L., Sprintall, J., and Herunadi, B.: Intraseasonal variability and tides in Makassar Strait, Geophys. Res. Lett., 27, 1499-1502, https://doi.org/10.1029/2000GL011414, 2000.

Susanto, R. D., Gordon, A. L., and Zheng, Q.: Upwelling along the coasts of Java and Sumatra and its relation to ENSO, Geophys. Res. Lett., 28, 1599-1602, https://doi.org/10.1029/2000GL011844, 2001.

Susanto, R. D., Ffield, A., Gordon, A. L., and Adi, T. R.: Variability of Indonesian throughflow within Makassar Strait, 2004-2009, J. Geophys. Res., 117, C09013, https://doi.org/10.1029/2012JC008096, 2012.
Susanto, R. D., Wei, Z., Adi, T. R., Zheng, Q., Fang, G., Bin, F., Supangat, A., Agustiadi, T., Li, S., Trenggono, M., and Setiawan, A.: Oceanography surrounding Krakatau Volcano in the Sunda Strait, Indonesia, Oceanography, 29, 228-237, https://doi.org/10.5670/oceanog.2016.31, 2016.

Syamsudin, F. and Kaneko, A.: Ocean variability along the southern coast of Java and Lesser Sunda Islands, J. Oceanogr., 69, 557570, https://doi.org/10.1007/s10872-013-0192-6, 2013.

Syamsudin, F., Kaneko, A., and Haidvogel, D. B.: Numerical and observational estimates of Indian Ocean Kelvin wave intrusion into Lombok Strait, Geophys. Res. Lett., 31, L24307, https://doi.org/10.1029/2004GL021227, 2004.

Tomczak, M. and Godfrey, J. S.: Regional Oceanography: An Introduction, Pergamon Press, Oxford, 1994.

Wijffels, S. and Meyers, G.: An intersection of oceanic waveguides: variability in the Indonesian throughflow region, J. Phys. Oceanogr., 34, 1232-1253, 2004.

Wijffels, S., Sprintall, J., Fieux, M., and Bray, N.: The JADE and WOCE I10/IR6 throughflow sections in the southeast Indian Ocean, Part 1: water mass distribution and variability, DeepSea Res. Pt. II, 49, 1341-1362, https://doi.org/10.1016/S09670645(01)00155-2, 2002.

Wu, Z. and Huang, N. E.: Ensemble empirical mode decomposition: a noise-assisted data analysis method, Adv. Adapt. Data Anal., 1, 1-41, https://doi.org/10.1142/S1793536909000047, 2009.

Wyrtki, K.: An equatorial jet in the Indian Ocean, Sciences, 181, 262-264, 1973.

Wyrtki, K.: Indonesian throughflow and the associated pressure gradient, J. Geophys. Res., 92, 12941-12946, 1987.

Yamagami, Y. and Tozuka, T.: Interannual variability of South Equatorial Current bifurcation and western boundary currents along the Madagascar coast, J. Geophys. Res.-Ocean., 120, 8551-8570, https://doi.org/10.1002/2015JC011069, 2015.

Yuan, Y., Chan, C. L. J., Wen, Z., and Chongyin, L.: Decadal and interannual variability of the Indian Ocean dipole, Adv. Atmos. Sci., 25, 856-866, https://doi.org/10.1007/s00376-008-0856-0, 2008.

Zhang, N., Feng, M., Du, Y., Lan, J., and Wijffels, S. E.: Seasonal and interannual variations of mixed layer salinity in the southeast tropical Indian Ocean, J. Geophys. Res.-Ocean. 121, 4716-4731, https://doi.org/10.1002/2016JC011854, 2016. 